\title{
Membrane traffic and fusion at post-Golgi compartments
}

\author{
Misoon Park and Gerd Jürgens* \\ Entwicklungsgenetik, Zentrum für Molekularbiologie der Pflanzen, University of Tübingen, Tübingen, Germany
}

Edited by:

Andreas P. M. Weber, University of

Duesseldorf, Germany

Reviewed by:

Marisa Otegui, University of

Wisconsin at Madison, USA

Chris Hawes, Oxford Brookes

University, UK

\section{${ }^{*}$ Correspondence:}

Gerd Jürgens, Entwicklungsgenetik,

Zentrum für Molekularbiologie der

Pflanzen, University of Tübingen, Auf

der Morgenstelle 3, 72076 Tübingen,

Germany.

e-mail: gerd.juergens@zmbp.

uni-tuebingen.de
Complete sequencing of the Arabidopsis genome a decade ago has facilitated the functional analysis of various biological processes including membrane traffic by which many proteins are delivered to their sites of action and turnover. In particular, membrane traffic between post-Golgi compartments plays an important role in cell signaling, taking care of receptor-ligand interaction and inactivation, which requires secretion, endocytosis, and recycling or targeting to the vacuole for degradation. Here, we discuss recent studies that address the identity of post-Golgi compartments, the machinery involved in traffic and fusion or functionally characterized cargo proteins that are delivered to or pass through post-Golgi compartments. We also provide an outlook on future challenges in this area of research.

Keywords: plant, trans-Golgi network, endosome, exocytosis, endocytosis, secretion, recycling
Several thousand proteins are delivered to their sites of action and turnover by membrane trafficking. Cargo proteins include vacuolar proteases, storage proteins, membrane-associated receptors and their soluble (secreted) peptide ligands, cell wall-modifying enzymes, nutrient and hormone transporters, ion channels, and PAMP receptors involved in pathogen defense. Thus, cellular homeostasis, cell-cell communication in development, and physiological responses to changes in the environment all depend on membrane traffic. In this review, we will summarize recent advances on post-Golgi membrane traffic covering compartments, trafficking pathways, and molecular players involved.

\section{DIVERSITY OF POST-GOLGI COMPARTMENTS}

Major ultrastructurally defined endomembrane compartments in post-Golgi trafficking are the trans-Golgi network (TGN), the multivesicular body (MVB)/prevacuolar compartment (PVC), and two types of vacuole, the lytic vacuole (LV) and the protein storage vacuole (PSV). Additional compartments such as the recycling endosome (RE) have been postulated or inferred from experimental studies or marker localization data but have not been identified ultrastructurally in plants (Figure 1).

\section{TRANS-GOLGI NETWORK/EARLY ENDOSOMES}

Secretory cargo proteins arrive at the TGN from the ER via the Golgi stacks. Originally described as partially coated reticulum (PCR; Pesacreta and Lucas, 1984; Tanchak et al., 1988), the TGN

\footnotetext{
Abbreviations: AALP, Arabidopsis aleurain like protein; ABA, abscisic acid; CCV, clathrin-coated vesicles; $\mathrm{CPI} 1$, cyclopropylsterol isomerase 1; ER, endoplasmic reticulum; PAMP, pathogen-associated molecular pattern; PIP5K2, phosphatidylinositol4-phosphate 5-kinase 2; PMEI1, pectin methylesterase inhibitor protein 1; PI3P, phosphatidylinositol-3-phosphate; RMR, receptor homology region transmembrane domain ring $\mathrm{H} 2$ motif protein; RPA, ROOT AND POLLEN ARF-GAP; SNARE, soluble $N$-ethylmaleimide-sensitive factor attachment receptor; SYP, syntaxin of plants; TFL1, TERMINAL FLOWER 1; TRAPP, transport protein particle; VAMP, vesicle-associated membrane proteins.
}

is a tubulo-vesicular compartment that is often closely associated with a Golgi stack but can also move away (Viotti et al., 2010; Kang et al., 2011). The TGN is a major sorting station for exocytic cargo proteins except that some storage proteins are sorted at the ER or cis-Golgi (Hara-Nishimura et al., 1998; Park et al., 2004). Importantly, the TGN also functions as an early endosome (EE) in plants, as revealed by time-course experiments with the lipophilic endocytic tracer FM4-64 (Dettmer et al., 2006). Thus, the TGN is at the intersection of the secretory and endocytic traffic. In addition, RAB-A class proteins related to the mammalian recycling Rab11 GTPase localize at a subpopulation of TGN (Chow et al., 2008; Kang et al., 2011). These observations suggest that distinct sorting functions are performed by the TGN, although there is no structural evidence for subdomains. TGN markers commonly used include the al subunit of the vacuolar $\mathrm{H}^{+}$-ATPase (VHA) and the Qc-SNARE SYP61 (Bassham et al., 2000; Sanderfoot et al., 2001; Dettmer et al., 2006). The latter has been used to identify the TGN proteome by mass spectrometry (Drakakaki et al., 2011). The TGN appears to be formed from the trans-most cisterna of the Golgi stack (Zhang and Staehelin, 1992), possibly by maturation. Its integrity seems to be maintained by anterograde traffic toward the plasma membrane (PM) and the vacuole as well as by retrograde traffic to the Golgi apparatus.

\section{PREVACUOLAR COMPARTMENT/MULTIVESICULAR BODIES}

Multivesicular bodies are ultrastructurally distinct, with intralumenal vesicles formed by local endosomal sorting complex required for transport (ESCRT)-mediated invaginations of the limiting membrane (Tse et al., 2004; Otegui and Spitzer, 2008; Stierhof and El Kasmi, 2010). MVBs act as a PVC and relay TGNsorted cargo proteins toward (lytic) vacuoles, thus functionally corresponding to the late endosomes (LE) of animal cells (Tse et al., 2004). A similar PVC [possibly related to the dark intrinsic protein (DIP) organelle] is also observed in trafficking to the PSV (Jiang et al., 2000; Shen et al., 2011) and might actually be identical 


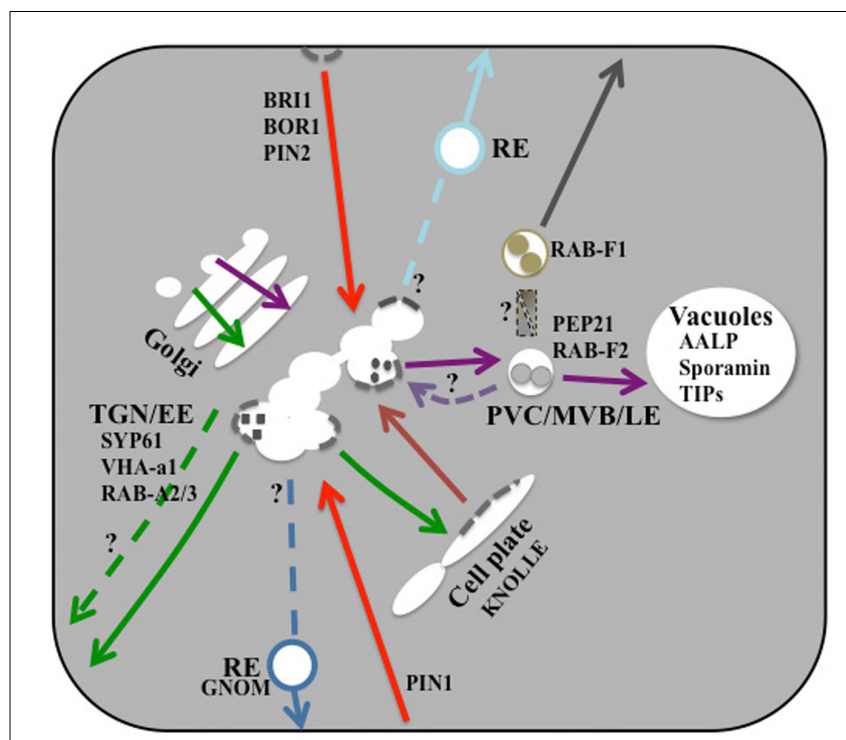

FIGURE 1 | Illustrated overview of post-Golgi traffic. In the vacuolar trafficking pathway (purple-colored), there is a controversy over the precise location where VSR recycling occurs (pale purple-colored dashed line). There are different populations of RAB-F-positive endosomes, but their origin is unknown. There is no clear evidence for multiple secretory pathways to the PM (indicated by the green-colored dashed line). Cell-plate formation mainly relies on the secretory pathway (green-colored). Molecular machineries involved in protein retrieval from the cell plate (salmon-colored) and in endocytosis (red-colored) may be similar, including clathrin (gray-colored dashed line). It is not clear whether clathrin is also involved in the vacuolar trafficking pathway. Although there seem to be multiple types of REs (blue and pale blue-colored), their origin and identity are unknown. Small-sized letters indicate representative molecular markers for post-Golgi trafficking pathways. For simplicity, polar location of BOR1 is not shown. For details, see the text.

to the PVC in lytic vacuolar traffic (Miao et al., 2008). By analogy with the non-plant systems in which LE fuse with the lysosome (reviewed in Luzio et al., 2010), it is generally accepted that MVBs fuse with the tonoplast, releasing the intralumenal vesicles, and their membrane-bound cargo into the vacuole for degradation (Scheuring et al., 2011). This has been demonstrated, for example, for the syntaxin KNOLLE, which is detected on the intralumenal vesicles of MVBs and on vesicles inside the vacuole at the end of cytokinesis (Reichardt et al., 2007).

The origin of the MVBs in plant cells is still controversial whereas the LE of yeast and mammals have been shown to mature from EEs (Rink et al., 2005; Poteryaev et al., 2010). On the one hand, Golgi/TGN-derived vesicles appear to fuse with one another to form pre-MVBs from which MVBs mature en route to the PSV in the Arabidopsis embryo (Otegui et al., 2006). On the other hand, a recent study of both Arabidopsis root cells and tobacco mesophyll protoplasts presents structural and functional evidence suggesting that MVBs mature from TGNs by being pinched off and forming ESCRT-mediated intralumenal vesicles (Scheuring et al., 2011). Although the recent data strongly support a maturation model, some points still remain to be resolved (see below). In animals, early to late endosomal maturation appears to occur by Rab5-Rab7 conversion (Poteryaev et al., 2010). However, the plant homolog of mammalian Rab5, ARA7/RAB-F2b GTPase, is not located at the TGN/EE in plants but at PVCs/MVBs (Lee et al., 2004; Reichardt et al., 2007). This difference suggests that the underlying molecular machineries might be different between animals and plants.

Prototypical MVB/PVC markers include ARA7/RAB-F2b GTPase and Qa-SNARE SYP2 paralogs (i.e., PEP12/SYP21 and VAM3/SYP22/SGR), which associate with or reside on the limiting membrane, respectively (Lee et al., 2004; Shirakawa et al., 2010; Uemura et al., 2010). PEP12/SYP21 and VAM3/SYP22/SGR were regarded as distinct membrane markers for two related compartments, the PVC and the vacuole, respectively. Recently, however, Uemura et al. (2010) demonstrated functional redundancy of the two syntaxins and also showed by double labeling that the two proteins largely colocalize on both endomembrane compartments. Additionally, MVBs are morphologically altered by treatment with wortmannin, an inhibitor of phosphatidylinositol3 kinase (PI3K), which causes swelling and vacuolation of PVCs and is thus commonly used to identify PVCs (Tse et al., 2004; Wang et al., 2009). However, wortmannin has additional effects on endosomes and also impairs endocytosis from the PM (Lam et al., 2007).

Recently, Foresti et al. (2010) proposed that a late PVC/MVB exists as an intermediate compartment between the PVC and the central vacuole in the tobacco leaf epidermis, which was based on the localization of the recycling-defective vacuolar sorting receptor (VSR) VSR2. However, the PVC marker RHA1/RAB-F2a (see also below) was used to visualize this late PVC/MVB. It is thus important to employ additional unique subcellular markers to verify the presumed existence of a novel late PVC (see also Bottanelli et al., 2011b).

\section{RECYCLING ENDOSOMES}

Recycling endosomes have not been identified morphologically in plants. However, they were first functionally demonstrated as the site of action of the brefeldin A (BFA)-sensitive ADP ribosylation factor (ARF)-guanidine nucleotide exchange factor (GEF), GNOM, which is required for the recycling of the auxin-efflux carrier PIN-FORMED1 (PIN1) to the basal PM in the root vasculature (Geldner et al., 2003). In contrast, GNOM function is not required for the recycling to the PM of AUXIN-RESISTANT1 (AUX1), PIN2, and PM-located $\mathrm{H}^{+}$-ATPase (Kleine-Vehn et al., 2006), which suggests the existence of multiple functionally distinct REs. Although the partial colocalization of GNOM with FM4-64 would be compatible with the notion that REs might be part of the TGN (Geldner et al., 2003), the two compartments seem to differ in BFA sensitivity (Geldner et al., 2009). Moreover, there is no direct ultrastructural evidence supporting a subdomain organization of the TGN that could be unambiguously related to distinct trafficking roles. Interestingly, ARA7/RAB-F2b-positive endosomes are morphologically abnormal in gnom mutant cells, resembling wortmannin-treated MVBs (Geldner et al., 2003). However, this effect might be indirect since GNOM does not localize at the PVCs/MVBs. Moreover, delivery of the brassinosteroid receptor BRI and the boric acid/borate exporter BOR1 from the PM to the PVCs/MVBs appears to target these proteins to the LV rather than recycling them back to the PM (Viotti et al., 2010). Thus, it is unlikely that the PVCs/MVBs serve as REs. Recently, RAB-Ale 
and RAB-Alg-positive endosomes were proposed to correspond to REs based on their higher sensitivity to BFA (Geldner et al., 2009). Obviously, additional structural and functional evidence is required to identify the REs unambiguously.

\section{VACUOLES}

Plant cells have different types of vacuoles with specific physiological and functional features, depending on the developmental stage (Marty, 1999). Two types of vacuoles have been best studied: (i) the $\alpha$-tonoplast intrinsic protein ( $\alpha$-TIP)-positive PSV that is built during embryogenesis and serves as an energy sink during seed germination; (ii) the $\gamma$-TIP-positive LV or central vacuole $(\mathrm{CV})$ that appears to derive from the PSV during germination and functions in degrading proteins and in sequestering secondary metabolites (Höfte et al., 1992; Zheng and Staehelin, 2011). The prevailing view was that multiple types of vacuole exist in a differentiated cell, as revealed by the distinct locations of $\alpha$-TIP and $\gamma$-TIP in Arabidopsis root or leaf cells (Paris et al., 1996; Park et al., 2004). However, this concept has been disputed in recent studies of $\alpha-, \gamma$-, and $\delta$-TIPs as well as storage proteins in barley, pea, and Arabidopsis (Hunter et al., 2007; Olbrich et al., 2007). The authors demonstrated that there is only a single type of (central) vacuole which is labeled with both $\alpha$-TIP and $\gamma$-TIP in various differentiated tissues (also reviewed in Frigerio et al., 2008). According to Sohn et al. (2007), a mutation of TFL1, a shoot meristem identity gene involved in flower development, results in defects in PSV trafficking. TFL1 is not only located at the PM and a PSV-like organelle but also colocalizes with the $\delta$ subunit of the AP-3 complex which was more recently shown to be involved in vacuolar biogenesis (see below for details). Although the PSV-like organelle remains to be characterized morphologically and functionally, its existence may imply the occurrence of hitherto unappreciated vacuolar functional diversity in differentiated cell types.

Commonly used markers include aleurain, sporamin, and $\gamma$ TIP for the LV/CV and lectin, globulin, albumin, and $\alpha$-TIP for the PSV (Höfte et al., 1992; reviewed in Robinson et al., 2005). Apart from the vacuoles themselves, there are additional compartments such as dense vesicles (DVs), precursor-accumulating compartments (PACs), and DIP-positive organelles that lie on the PSV trafficking pathways (Hohl et al., 1996; Shimada et al., 1997; Jiang et al., 2000; Hillmer et al., 2001).

\section{CELL PLATE}

Plant cells generate a transient membranous compartment named cell plate in the plane of cell division during cytokinesis. Formation of the cell-plate starts in the center and progresses toward the periphery until the margin of the cell-plate fuses with the parental PM (Seguí-Simarro et al., 2004; reviewed in Jürgens, 2005). The cell plate is mainly built by homotypic fusion of Golgi/TGN-derived vesicles whose delivery to the plane of cell division is guided by the dynamic cytoskeletal array of phragmoplast microtubules (reviewed in Jürgens, 2005; Reichardt et al., 2007). By contrast, endocytosis seems to participate in the recruitment of the cortical division zone (Van Damme et al., 2011). A commonly used marker for the plane of cell division and the forming cell plate is the cytokinesis-specific syntaxin/Qa-SNARE KNOLLE/SYP111 (Lauber et al., 1997).

\section{POST-GOLGI TRAFFICKING PATHWAYS LATE SECRETORY PATHWAY(s) TO THE PLASMA MEMBRANE}

Traffic of soluble proteins from the ER to the PM and out of the cell occurs by default, the only requirement being an $\mathrm{N}$-terminal signal peptide for protein translocation across the ER membrane, as shown for several soluble enzymes as well as GFP (Denecke et al., 1991; Batoko et al., 2000). Conversely, a key regulator of Arabidopsis stem-cell homeostasis, the peptide ligand CLAVATA 3 (CLV3), which is normally secreted from the cell, was diverted to the vacuole when fused to a C-terminal vacuolar sorting signal (Rojo et al., 2002). Thus, the absence of a sorting signal for vacuolar trafficking is required for secretion of soluble proteins, supporting the notion that secretion is a default pathway.

Secretory trafficking of membrane proteins is less well characterized. Membrane proteins with a single transmembrane domain appear to reach their destination along the secretory pathway according to the length of their hydrophobic region: proteins with a shorter membrane span are held back in the Golgi stack whereas those with a longer membrane span are trafficked to the PM (Brandizzi et al., 2002). The situation might be different for other membrane proteins such as those with multiple membrane spans or those with a hydrophobic tail anchor such as SNARE proteins that are inserted into the ER membrane by the GET machinery (Borgese and Fasana, 2011). For example, the rice secretory carrier membrane protein 1 (SCAMP1) has four transmembrane domains of which two domains appear to mediate export from the Golgi stack and another one appears to mediate traffic from the TGN to the PM (Cai et al., 2011).

Concanamycin A (ConcA) inhibits the activity of the TGN/EEresiding VHA. As a consequence, TGN and MVB are incorporated into the Golgi apparatus, and the Golgi stacks are morphologically altered as well. Consequently, ConcA blocks downstream pathways of the TGN/EE (Dettmer et al., 2006; Reichardt et al., 2007; reviewed in Robinson et al., 2008). Interestingly, ConcA inhibits the secretion of secGFP at the TGN/EE (Viotti et al., 2010), but other markers are not affected (Scheuring et al., 2011). Thus, one or more pathway(s) might be involved in the secretion of soluble proteins. Additional functional studies are required to resolve this issue.

\section{TRAFFICKING TO THE CELL DIVISION PLANE AS A SPECIALIZED SECRETORY PATHWAY}

Phragmoplast-assisted cell-plate formation is a unique mode of cytokinesis that evolved in the plant lineage only. Golgi/TGNderived membrane vesicles that deliver the necessary material for building the PM and the cell wall are targeted to the plane of cell division (Seguí-Simarro et al., 2004). The available evidence suggests that both secretory and endocytic traffic contribute to cell-plate formation (Dhonukshe et al., 2006; Reichardt et al., 2007, 2011). Interestingly, cell-plate formation is critically dependent on secretory traffic delivering de novo synthesized KNOLLE syntaxin whereas endocytic traffic appears to be a consequence of preventing recycling of internalized membrane proteins to the PM (Reichardt et al., 2011). Many proteins that are detected at the PM during interphase accumulate at the plane of division during cytokinesis (Steinmann et al., 1999; Zuo et al., 2000). However, only cycling PM proteins arrive at the division plane by endocytosis 
whereas non-cycling PM proteins such as SYP132 have to be newly synthesized and delivered by secretion to accumulate at the forming cell plate (Reichardt et al., 2011). This observation may also indicate that protein trafficking to the cell-plate relies on a default pathway. How KNOLLE syntaxin reaches the plane of cell division has been analyzed in transgenic plants expressing chimeric syntaxins in which protein domains have been swapped between KNOLLE and MVB-localized PEP12/SYP21 (Touihri et al., 2011). KNOLLE syntaxin with its tail anchor replaced by that of the prevacuolar syntaxin PEP12 still reaches the cell plate and rescues a knolle mutant whereas an N-terminal region from PEP12 targets the chimeric protein to the MVB/PVC (Touihri et al., 2011). This result supports the notion of trafficking to the plane of cell division being a default pathway.

\section{ENDOCYTOSIS AND RECYCLING TO THE PLASMA MEMBRANE VS. TARGETING TO THE VACUOLE FOR DEGRADATION}

Upon internalization from the PM, endocytosed proteins face two options: They may be recycled to the PM or they may be passed on to the vacuole for degradation. In Arabidopsis, many PM proteins including auxin-efflux carriers PIN1 and PIN2, brassinosteroid receptor BRI1 and boron transporter BOR1 undergo constitutive endocytosis and recycling (Steinmann et al., 1999; Geldner et al., 2003, 2007; Geldner and Jürgens, 2006; Takano et al., 2010). There are only a few exceptions known such as the Qa-SNARE SYP132, which does not constitutively cycle and rather stays at the PM (Reichardt et al., 2011). Constitutive cycling of PM proteins was initially revealed for PIN1 by treating seedling roots with the fungal toxin brefeldin A (BFA), which trapped internalized PIN1 reversibly in endosomal BFA compartments (Geldner et al., 2003). BFA prevents ARF GTPase activity by inhibiting GDP-GTP exchange through the cognate BFA-sensitive regulator ARF-GEF (see below). In the case of PIN1 recycling, the ARF-GEF GNOM is the BFA target, as indicated by its co-localization with PIN1 trapped in BFA compartments and by BFA-insensitive PIN1 recycling to the $\mathrm{PM}$ in the presence of engineered BFA-resistant GNOM (Geldner et al., 2003). In contrast to PIN1, GNOM is not essential for recycling of PIN2, AUX1, and PM-H ${ }^{+}$-ATPase (Geldner et al., 2003). Thus, there are also GNOM-independent recycling pathways from endosomes to the PM.

Clathrin-mediated endocytosis in plants has been demonstrated for PIN proteins and the endocytic tracer FM4-64, using both overexpression of the dominant-negative hub fragment of the clathrin heavy chain and T-DNA insertional clathrin heavy chain mutants (Dhonukshe et al., 2007; Robert et al., 2010; Kitakura et al., 2011). Wortmannin has also been widely used to interfere with endocytosis (Emans et al., 2002; Reichardt et al., 2007; Ebine et al., 2011), in addition to its known disruptive effects on vacuolar trafficking, although this drug has rather ill-defined effects on endosomes (see above). Wortmannin was recently shown to cause aggregation of clathrin at the PM, which might explain the inhibitory effect of wortmannin on endocytosis (Ito et al., 2011).

Clathrin is also involved in the retrieval of PIN protein from the cell plate where PIN interacts with dynamin-related protein $1 \mathrm{~A}$ (DRP1A; see below; Mravec et al., 2011), although clathrin often does not clearly colocalize with DRP1A at the cell plate (Ito et al., 2011). Thus, the molecular machinery of protein retrieval from the cell-plate appears to be similar to that of endocytosis. Whereas PIN1 is endocytosed from the cell plate and then retargeted to the PM, the cytokinesis-specific syntaxin KNOLLE/SYP111 is endocytosed and then delivered to the LV for degradation (Reichardt et al., 2007). Hence there must be a selective sorting mechanism, possibly at the TGN or cell plate (see below).

Clathrin-mediated endocytosis in mammalian cells also involves the AP-2 complex, with its $\mu$-adaptin subunit selecting cargo with a tyrosine-based sorting motif for internalization from the PM (reviewed in Boehm and Bonifacino, 2001). Tyrphostin A23 is a competitive inhibitor of the interaction of the sorting sequence $\mathrm{Yxx} \phi$ (where $\mathrm{Y}$ is a tyrosine, $\mathrm{x}$ is any amino acid, and $\phi$ is a bulky hydrophobic residue) of cargo proteins with the medium ( $\mu 2$ ) subunit of mammalian AP-2 complex, and this has been used to explore clathrin-dependent trafficking pathways (Banbury et al., 2003). In plants, tyrphostin A23, but not its structural analog tyrphostin A51, inhibits endocytosis of FM4-64, and the artificially expressed human transferrin receptor (Ortiz-Zapater et al., 2006; Dhonukshe et al., 2007). Although tyrphostin A23 appears to have non-specific deleterious effects in plant cells (see below), the inhibitory effect of tyrphostin A23 might result from the existence of a plant equivalent to $\mu 2$ adaptin, which has not been identified. There is also clathrin-independent endocytosis which, however, has not been well analyzed in plants. So far, a distinct route of endocytosis has been demonstrated by ultrastructural tracing of charged nanogold in the presence of ikarugamycin, which inhibits clathrin-dependent endocytosis (Moscatelli et al., 2007; Onelli et al., 2008). It will be important to study the underlying mechanism of this presumed novel endocytic route at the molecular level.

If not recycled, $\mathrm{PM}$ proteins are delivered, via PVCs/MVBs, to the LV for degradation (Kleine-Vehn et al., 2008; Viotti et al., 2010). It is not at all clear where the two routes of recycling and degradation diverge among the post-Golgi endosomal compartments in plants. All endocytosed PM proteins are delivered to the TGN/EE. If the MVBs indeed mature from some subdomain of TGNs and the REs are also derived from TGNs, the sorting would likely occur at the TGNs (see above). Apart from the difficulty of ultrastructurally identifying REs, there are conflicting (or incomplete) data regarding the recycling vs. degradation. For example, the sorting nexin 1 (SNX1)-labeled PVC/MVB has been proposed to be the site of sorting (Jaillais et al., 2006). However, PM proteins to be recycled have not been detected at the PVC/MVB (Viotti et al., 2010). Instead, the recycling pathway might be affected indirectly by interfering with vacuolar trafficking.

Ubiquitination is likely an endocytic signal for PM proteins to be targeted to the vacuole for degradation (Abas et al., 2006; Kleine-Vehn et al., 2008). After having been trafficked to the endosomes, ubiquitinated proteins seem to be recognized by ESCRTs complexes, which in turn promote MVB formation (Spitzer et al., 2006; Otegui and Spitzer, 2008). For example, PIN1, PIN2, and AUX1 proteins are known cargo proteins of the ESCRT machinery (Spitzer et al., 2009). As an example for ligand-dependent endocytosis, the immunity-related pattern recognition receptor FLS2 is degraded in response to ubiquitination and BAK1-mediated phosphorylation triggered by the bacterial elicitor flagellin 22 (Lu et al., 2011). Similarly, endocytosis of IRON-REGULATED 
TRANSPORTER 1 (IRT1) and traffic of BOR1 from the PM to the LV depend on their ubiquitination (Barberon et al., 2011; Kasai et al., 2011).

\section{VACUOLAR CARGO TRAFFICKING PATHWAY(s)}

Newly synthesized soluble cargo proteins destined to the vacuoles need an $\mathrm{N}$ - or a C-terminal vacuolar sorting sequence (known as NTPP or CTPP), as supported by the vacuolar trafficking of NTPPtagged ER-translocated secGFP (Di Sansebastiano et al., 1998). Generally, LV- and PSV-destined soluble cargo proteins have NTPP and CTPP, respectively, as sorting sequences that are thought to bind to corresponding VSRs for targeted delivery. VSR1/ELP (one of seven homologs), for example, recognizes the N-terminal sorting sequence, NPIR, of AALP or sporamin at the TGN/EE for sorting, and delivery to the MVB/PVC (Sanderfoot et al., 1998; Ahmed et al., 2000). However, this notion was questioned recently by the observation that transiently expressed ER-anchored pea VSR caused retention of soluble vacuolar cargo molecules in the ER (Niemes et al., 2011), suggesting that sorting to the vacuole may occur at an earlier step. More direct evidence is needed to identify the endomembrane compartment(s) at which VSRs interact with their vacuolar cargo proteins normally.

The VSR1/ELP interacts with the $\mu 1$ medium subunit of the mammalian AP-1 complex and with Arabidopsis $\mu \mathrm{A}$-adaptin in vitro through a tyrosine residue-based sorting sequence, YMPL (Sanderfoot et al., 1998; Ahmed et al., 2000), implying that clathrin-coated vesicles (CCVs) are likely involved in vacuolar trafficking. However, this idea was challenged by the recent observation that transient overexpression of the truncated clathrin heavy chain, the so-called clathrin hub, does not interfere with vacuolar trafficking, which was consistent with the alternative MVB maturation model (Scheuring et al., 2011). However, it is not known how efficiently the clathrin hub interferes with CCV formation (see below), although endocytosis of FM4-64, PIN1, and PIN2 proteins is clearly inhibited (Dhonukshe et al., 2007; Scheuring et al., 2011). Moreover, the MVB maturation model does not explain why a mutation of the adaptor protein (AP) complex-recognition sequence, YMPL, of pea VSR causes its mistargeting in tobacco protoplasts (daSilva et al., 2006) and why homodimerizationdefective VSR1 is less detected in a CCV-enriched fraction in Arabidopsis leaf than is pea VSR (Kirsch et al., 1994; Kim et al., 2010). Arabidopsis VSR2 and a lily ortholog, LIVSR, have been reported to localize at the PM in germinating lily or tobacco pollen tubes (Wang et al., 2010, 2011). However, the significance of this observation for the regulation of vacuolar sorting is entirely unclear.

Unlike vacuolar trafficking of soluble cargo proteins, not much is known about sorting mechanisms of membrane proteins. At $\beta$ Fructosidase 4 ( $\beta$ Fruct4) appears to require multiple specific sequences for stepwise sorting from the TGN via the MVB to the vacuole in Arabidopsis (Jung et al., 2011). In the tobacco epidermis, differential trafficking mechanisms are involved in the vacuolar trafficking of several membrane proteins tested (Bottanelli et al., 2011a).

Generally, soluble cargo proteins are thought to be released from VSR at the PVCs/MVBs, although there is no conclusive molecular evidence for this. Whereas soluble cargo proteins are delivered to the vacuole via membrane fusion of the PVCs/MVBs with the vacuole (Scheuring et al., 2011), VSR was presumed to be recycled from the PVCs/MVBs to the TGN/EE by the retromer complex (Sanderfoot et al., 1998; daSilva et al., 2005; Oliviusson et al., 2006; Jaillais et al., 2007). However, this long-held belief has recently been questioned by the controversial localization of the retromer complex to the TGN, rather than the MVB, in Arabidopsis and tobacco (Jaillais et al., 2006, 2007, 2008; Niemes et al., 2010; Pourcher et al., 2010). The localization of the retromer complex to the TGN would be consistent with the maturation model for the origin of the MVB (see above).

Fusion of the PVCs/MVBs with the vacuole may require QaSNARE SYP2 proteins and the homotypic fusion and protein sorting/class C-VPS protein (HOPS/C-VPS) complex comprising the Arabidopsis VPS16-homolog VCL1, VPS11, and VPS33 (Rojo et al., 2001, 2003; Shirakawa et al., 2010). However, the latter two proteins have yet to be functionally studied.

Different trafficking pathways to the PSV have been shown in diverse species including pumpkin, bean, and Arabidopsis (Frigerio et al., 1998; Hara-Nishimura et al., 1998; Hinz et al., 1999; Park et al., 2004, 2005). RMRs are suggested to be PSV sorting receptors in Arabidopsis, tobacco, and rice (Jiang et al., 2000; Park et al., 2005, 2007; Hinz et al., 2007). RMRs were studied in Arabidopsis and rice. RMR1 and RMR2 have been localized at the Golgi, a PVC-like organelle and the PSV (or protein bodies); these proteins interact with the C-terminal vacuolar sorting sequences of storage proteins in vitro (Park et al., 2005, 2007; Hinz et al., 2007). Unlike VSRs in lytic vacuolar traffic, RMRs appear not to be recycled and instead are bound to the aggregates of soluble cargo proteins (Park et al., 2007). More recent mutant studies in Arabidopsis have challenged the role of RMRs in PSV trafficking and identified VSR1, VSR3, and VSR4 as the major sorting receptors that function redundantly in the targeting of soluble cargo proteins to the PSV and the LV/CV (Shimada et al., 2003; Zouhar et al., 2010). This result suggests that VSRs presumably fulfill multiple functions and that vacuolar biogenesis of PSV and LV/CV might be closely linked, especially in early embryogenesis.

\section{ASYMMETRIC LOCALIZATION OF PLASMA-MEMBRANE PROTEINS}

Most PM proteins are located in the PM all around the cell rather than being confined to a specific surface area (Geldner and Jürgens, 2006; Geldner et al., 2007). However, several PM proteins localize polarly or asymmetrically, i.e., on one side of the cell (Steinmann et al., 1999; Swarup et al., 2004; Takano et al., 2005, 2010). These include several members of the PIN family of auxinefflux carriers as well as other PM proteins such as BOR1 and its paralog BOR4 (Miwa et al., 2007), the boron importer NIP5;1 (Takano et al., 2010), exporter PIS1/PDR9/ABCG37 of the plant hormone precursor indole-3-butyric acid (Langowski et al., 2010), the Casparian strip membrane domain proteins CASPs in the endodermis (Roppolo et al., 2011), and the ABCG-type transporter DSO/AtWBC11 in the epidermis (Panikashvili et al., 2007). In addition, the GPI-anchored COBRA protein is present only on the lateral surfaces of root vascular cells (Schindelman et al., 2001). How the polar localization comes about has not been well studied in most cases. For PIN1, however, it was demonstrated that the 
initial accumulation in the PM is non-polar, which might reflect non-polar secretory trafficking, whereas endocytosis and targeted recycling bring about the polar localization of PIN1 (Dhonukshe et al., 2008). PIN1 is actively localized at the basal PM in the root vasculature by the ARF-GEF GNOM and PP2A phosphatases that counteract the PINOID kinase (Steinmann et al., 1999; Michniewicz et al., 2007). In contrast, PIN2 localizes at the PM apically and basally in the epidermis and cortex, respectively, and only the basal localization seems to be dependent on GNOM function (Geldner et al., 2003). In general, apical targeting of PIN proteins requires the PINOID kinase and its homologs WAG1 and WAG2, which phosphorylate their PIN substrates (Dhonukshe et al., 2010). Additionally, the sterol composition mediated by the ER-residing CPI1 affects PIN2 redistribution after cytokinesis (Men et al., 2008). PIN3, which is required for phototropism, locates polarly at the PM of epidermis, cortex, endodermis, and vasculature, but apolarly in the columella (Friml et al., 2002). Upon shading, PIN3 relocates polarly toward the inner membrane of the endodermis, which depends on the function of GNOM and PINOID, and thus triggers apical hook development (Ding et al., 2011). Whereas the polar localization of some PIN transporter might reflect the (changeable) direction of auxin flow, the polar localization of other PM proteins might rather reflect the intrinsic polarity of the cell in which they are expressed. This might apply to DSO in the outer PM of the epidermis or BOR1 in the inner $\mathrm{PM}$ of various root cells including the epidermis, endodermis, and columella. BOR1 accumulation, but not its polarity, responds to changes in the external supply of boron. BOR 1 cycles between the $\mathrm{PM}$ and endosomes when the external concentration of boron is low; however, BOR1 is fast endocytosed and delivered to the LV when the root is exposed to a high concentration of boron (Takano et al., 2005, 2010). Tyrosine residues appear to be important in BOR1 turnover (Takano et al., 2010), although their specific role is not clear.

\section{MOLECULAR PLAYERS OF POST-GOLGI TRAFFIC VESICLE FORMATION BY ARF GTPases AND THEIR REGULATORS, ARF-GEFs, AND ARF-GAPs}

Small GTPases of the ARF family recruit coat proteins by undergoing GTP/GDP exchange cycles that are tightly controlled by specific regulatory proteins, ARF-GEFs, and ARF-GAPs. The Arabidopsis genome encodes approx. one dozen ARF GTPases; the precise number is unknown because divergent ARFs cannot easily be distinguished from functionally distinct ARLs (ARF-LIKE proteins). Of the three eukaryotic ARF classes, only ARF1 isoforms are present in plants, which, on the other hand, also have plant-specific ARF classes such as ARFA and ARFB (and possibly additional ARF classes; Jürgens and Geldner, 2002). ARF1 predominantly accumulates at the TGN/EE and the Golgi stacks and thus likely recruits both COPI and AP complex/clathrin coat proteins (Pimpl et al., 2000; Matheson et al., 2007; Stierhof and El Kasmi, 2010). Barley isoforms of ARF1 named ARFA1b/1c function in callose deposition and preinvasive basal defense and have been localized to MVBs (Böhlenius et al., 2010). However, this localization has been disputed (Robinson et al., 2011). Plant-specific ARFB was detected at the PM and proposed to be the plant equivalent of mammalian ARF6, although no functional assays have been performed
(Matheson et al., 2008). Moreover, there is no ortholog of the mammalian ARF6 exchange factor EFA6 in Arabidopsis.

The Arabidopsis genome encodes eight ARF-GEFs that are all $150-220 \mathrm{kDa}$ in size and can be grouped into two clades related to human GBF1 and BIG, respectively (Anders and Jürgens, 2008). Importantly, BFA can be used to conditionally inactivate specific ARF-GEFs and thus determine the trafficking pathways these ARF-GEFs regulate. Sensitivity or resistance to BFA critically depends on specific amino acids in the catalytic SEC7 domain of ARF-GEFs, which forms the basis for engineering fully functional BFA-sensitive or BFA-resistant variants of ARF-GEFs (Geldner et al., 2003; Richter et al., 2007). BFA-sensitive GNOM regulates endosomal recycling of PIN1 and PIN3 proteins (Geldner et al., 2003; Ding et al., 2011), but only partially the recycling of PIN2 and PM-localized $\mathrm{H}^{+}$-ATPase (Geldner et al., 2003), which suggests the existence of multiple recycling pathways. A similar conclusion could be drawn from the observation that the small compound endosidin 1 has differential effects on endocytic trafficking of several proteins tested (Robert et al., 2008). Additionally, GNOM functionally complements its closest homolog GNOMLIKE 1 (GNL1), which is BFA-insensitive and functions in COPI complex recruitment at the Golgi stacks in retrograde traffic to the ER (Richter et al., 2007). Recently, GNOM was proposed to act in the internalization of FM4-64 at the PM (Naramoto et al., 2010). The third GBF1-related ARF-GEF, GNOM-LIKE 2 (GNL2) is required for pollen germination (Jia et al., 2009). GNL2 appears to be functionally related to GNOM, being able to mediate polar recycling of PIN1 when ectopically expressed in the seedling root (Richter et al., 2011). Interestingly, GNOM and GNL2 promote polar growth of root hairs and pollen tubes, respectively (Richter et al., 2011). The BIG clade comprises five members. Not much is known about BIG1 to BIG4. The catalytic SEC7 domain of BIG3 (originally designated BIG2) was demonstrated to catalyze the nucleotide exchange on ARF1 in vitro in a BFA-insensitive manner (Nielsen et al., 2006). BIG5 (also known as MIN7 or BEN1) was shown to play a role in immunity, being degraded in response to its interaction with the HopM1 effector of Pseudomonas (Nomura et al., 2006). Additionally, BIG5 might act in the trafficking of PIN1, PIN2, and PM-ATPase from the TGN/EE to the RE (Tanaka et al., 2009).

The Arabidopsis genome encodes 15 ARF-GAPs that are grouped into four different classes (Jürgens and Geldner, 2002). Class 1 ARF-GAP VASICULAR NETWORK DEFECTIVE 3 (VAN3), also known as SCARFACE (SFC) and ARF-GAP domain protein 3 (AGD3), locates at the TGN (Koizumi et al., 2005; Sieburth et al., 2006). More recently, VAN3 was proposed to be a putative ARF-GAP counteracting GNOM at the PM by regulating endocytosis of PIN1 (Naramoto et al., 2010). NEVERSHED (NEV)/AGD5, an ortholog of yeast Age2, functions in the trafficking of cargo molecules for floral organ abscission at the TGN/EE and RAB-A1-positive endosomes (Liljegren et al., 2009). RPA and AGD1 were shown to act in root hair growth (Song et al., 2006b; Yoo et al., 2008). The rice ARF-GAP OsAGAP is involved in vesicle traffic in the auxin-influx pathway (Zhuang et al., 2006). However, the ARF-substrate specificity of ARF-GAPs has been barely analyzed. For example, ARF-GAPs AGD5, AGD7, and RPA were shown to activate ARF1 in vitro (Song et al., 2006b; Min et al., 2007; 
Stefano et al., 2010). In addition, AGD5 was shown to interact also with ARFB in vitro (Stefano et al., 2010). Interestingly, AGD7 interacts with ARF1 in vivo, and overexpression of AGD7 inhibits $\gamma \mathrm{COP}$ recruitment to the Golgi membrane and also disrupts anterograde ER-Golgi traffic (Min et al., 2007).

\section{MEMBRANE VESICLE COAT PROTEINS}

Unlike mammals, Arabidopsis lacks the equivalent of caveolin coat protein. Furthermore, stonin and Golgi-localizing $\gamma$-ear homology, ARF-binding protein (GGA) are not found in Arabidopsis (Boehm and Bonifacino, 2001). Thus, clathrin presumably plays a major role in plant post-Golgi traffic by binding to AP complexes. Non-coated secretory vesicles (SV) have been observed at the Golgi/TGN by electron tomography and proposed to deliver mainly secretory cargo proteins to the PM (Staehelin et al., 1990; Kang et al., 2011). However, the functional significance of the non-coated vesicles has not been demonstrated.

The Arabidopsis genome encodes three and two homologs of clathrin light chain and clathrin heavy chain, respectively, which have been detected at the TGN, the cell plate, and the PM (Otegui et al., 2001; Dhonukshe et al., 2007; Mravec et al., 2011). Recently, the clathrin light chain was also shown to be associated with ARA6/RAB-F1-positive MVBs, but not with RHA1/RAB-F2apositive MVBs (Ito et al., 2011). To date, however, there is no report on the participation of clathrin plaques in membrane invagination at the MVBs in plants, although a thick layer of ESCRTs complexes had been observed at the limiting surface of PVCs/MVBs (Tse et al., 2006; Stierhof and El Kasmi, 2010). Thus, further analysis is needed to define the role of clathrin at ARA6/RAB-F1-positive MVBs.

Up to now, functional and pharmacological analyses have demonstrated the involvement of clathrin in endocytosis in Arabidopsis and tobacco (Dhonukshe et al., 2007; Zhao et al., 2010; Kitakura et al., 2011). Tyrphostin A23 is broadly used to explore clathrin-dependent trafficking pathways (Banbury et al., 2003; Ortiz-Zapater et al., 2006; Dhonukshe et al., 2007). However, tyrphostin A23 appears to have non-specific deleterious effects in Arabidopsis and tobacco cells (I. Reichardt and G. Jürgens, unpublished data; also reviewed in Robinson et al., 2008). Hence, proper controls are absolutely necessary to distinguish specific from non-specific interference when tyrphostin A23 is used to study membrane traffic.

The clathrin hub has been used to interfere with clathrinmediated trafficking pathways in mammals and plants (Liu et al., 1995; Dhonukshe et al., 2007). This fragment comprises the Cterminal third of the clathrin heavy chain and is supposed to compete with the endogenous clathrin heavy chain in interacting with clathrin light chains (Liu et al., 1995). Fortunately, the finding of clathrin-dependency in endocytosis that had been revealed by the combinational approaches of the clathrin hub overexpression and tyrphostin A23 was consistent with the results of a functional study of clathrin heavy chain mutants (Dhonukshe et al., 2007; Robert et al., 2010; Kitakura et al., 2011). Based on both clathrin hub overexpression and ultrastructural analysis of PVC/MVB, the vacuolar trafficking pathway was proposed to be clathrin-independent (Scheuring et al., 2011). In our knowledge, however, it is not fully explained how the clathrin hub interferes with CCV formation at the molecular level in plants. For example, do all three clathrin light chain proteins have the same affinities for the clathrin hub? Thus, an in-depth functional study of clathrin is needed to elucidate fully the role of clathrin in plant membrane traffic.

Heterotetrameric AP complexes recognize a tyrosine- or dileucine-based sorting motif of cargo molecules, which in turn recruit cytosolic clathrin to the membrane for CCV formation. Although the sequence similarity of adaptins with their mammalian counterparts reveals four different types of AP complexes and five homologs of the $\mu$ subunit (named as $\mu \mathrm{A}-\mu \mathrm{D}$ instead of $\mu 1-\mu 4)$ in Arabidopsis (Boehm and Bonifacino, 2001), they have been hardly studied in plants. In addition, the existence of an additional AP complex (AP-5) locating at the LE has been recently demonstrated in mammalian cells; their homologs $(\mu 5, \beta 5$, and $\zeta)$ were found in Arabidopsis and Physcomitrella patens by sequence similarity, even though their corresponding sigma subunit $(\sigma 5)$ was not found yet (Hirst et al., 2011).

The AP-3 complex consisting of $\delta / \beta 3 / \mu \mathrm{D} / \sigma 3$ seems to be involved in vacuolar biogenesis (Feraru et al., 2010; Zwiewka et al., 2011). Interestingly, elimination of the AP-3 complex appears to have no obvious phenotypic effect. However, the knockout alleles of AP- 3 subunits $\beta$ and $\delta$ suppress the zigzag (zig) phenotype of plants lacking the vacuolar trafficking Qb-SNARE VTI11, and zig suppressor 4 (zip4) was identified as a loss-of-function allele of $\mu \mathrm{D}$ adaptin (Niihama et al., 2009). $\mu \mathrm{A}$ was proposed to be the putative medium subunit of the AP-1 complex as inferred from the localization at the trans-Golgi in Arabidopsis and from the in vitro interaction with the tyrosine sorting sequence of VSR-PS1 or TGN38 (Happel et al., 2004). However, there is no functional in vivo evidence supporting this notion. The ENTH-domain containing monomeric adaptor, Epsin 1 is functionally involved in vacuolar trafficking, but not in the secretory pathway (Song et al., 2006a). Epsin R2 interacts in vitro with the AP-3 complex and VTI12, giving a hint at its involvement in PSV traffic (Lee et al., 2007). The ANTH-domain-bearing monomeric adaptor AP180 interacts with At $\alpha \mathrm{C}$-adaptin, one of putative large subunits of AP-2 (Barth and Holstein, 2004).

\section{VESICLE BUDDING BY DYNAMIN-RELATED GTPases}

Dynamin-related proteins (DRPs) are GTPases that constrict or pinch off membranes and thus function in vesicle budding from diverse endomembrane compartments such as the PM, cell plate, and Golgi/TGN and also mediate fission of mitochondria and plastids (reviewed in Praefcke and McMahon, 2004; reviewed in Pucadyil and Schmid, 2009). DRP2B/ADL6 is involved in the vacuolar trafficking pathway (Jin et al., 2001; Lam et al., 2002). Moreover, DRP2B/ADL6 and DRP1A/ADL1 participate in CCV formation at the PM and cell plate (Fujimoto et al., 2010; Mravec et al., 2011). DRP2A and DRP2B are functionally redundant, localize to the tip of root hairs where endocytosis occurs and play an essential role in gametophyte development (Taylor, 2011). Rice BRITTLE CULM 3/OsDRP2B mediates vesicle trafficking involved in cellulose biosynthesis (Li et al., 2010).

\section{VESICLE TETHERING BY RAB GTPases AND TETHERING FACTORS}

Tethering of transport vesicles to their target membrane requires RAB GTPases and their effector proteins whereas the subsequent fusion of the membranes is mediated by the SNARE fusion 
machinery and its regulators. The Arabidopsis genome encodes 57 RAB GTPases representing eight clades A-H (Rutherford and Moore, 2002).

Arabidopsis RAB-E1d, which is related to mammalian Rab8 and yeast Ypt2, locates at the Golgi, regulates the secretory pathway, but not the vacuolar pathway, in the tobacco leaf epidermis, and interacts with PM-residing PIP5K2 (Camacho et al., 2009; Bottanelli et al., 2011a).

RAB-A2 and RAB-A3 localize at the VHA-a1-positive TGN and also at the growing margin of the cell plate during cytokinesis (Chow et al., 2008). In contrast, tobacco NtRAB11b labels Golgi stacks in the apical clear zone of growing pollen tubes; GDP-locked NtRAB11b inhibits traffic of exocytic and recycling vesicles to the pollen tube tip (de Graaf et al., 2005). RAB-A4b affecting both root hair and pollen tube growths preferentially labels the TGN and cell-wall materials-containing SV near the PM in growing tips (Preuss et al., 2004, 2006; Szumlanski and Nielsen, 2009; Kang et al., 2011). These findings suggest a role for RAB-A class proteins, which are related to mammalian recycling Rab11 and yeast Ypt3, in exocytosis and recycling pathways. This idea might be also supported by the observation that null mutations eliminating subunits of TRAPPII, which is a putative GEF for RAB-A1c, inhibit the secretory pathway, but not vacuolar traffic (Qi et al., 2011).

There are three RAB-F class proteins in Arabidopsis. Whereas RHA1/RAB-F2a and ARA7/RAB-F2b colocalize at the PVCs/MVBs (Lee et al., 2004; Reichardt et al., 2007), plant-specific ARA6/RAB-F1 locates in differential populations of the endosomes, although their localizations overlap to some extent (Ueda et al., 2001, 2004). Additionally, ARA6/RAB-F1 is more resistant to BFA than is ARA7/RAB-F2b (Ueda et al., 2004). While the GDP-locked mutant of RAB-F2 proteins inhibits vacuolar targeting of AALP in Arabidopsis transient assays, the homologous mutation of plant-specific ARA6/RAB-F1 does not (Ueda et al., 2001; Sohn et al., 2003), suggesting that only RAB-F2 proteins act in vacuolar traffic. However, overexpression of the nucleotide-free ARA6/RAB-F1 was recently shown to cause mistargeting of vacuolar soluble cargo proteins to the apoplast in the tobacco epidermis (Bottanelli et al., 2011a). Similarly, a putative ARA6/RAB-F1 ortholog, $\mathrm{m}-\mathrm{Rab}_{\mathrm{mc}}$ in Mesembryanthemum, was also proposed to be involved in vacuolar targeting at the PVCs/MVBs (Bolte et al., 2004). However, the loss-of-function mutant of ARA6/RAB-F1 did not disturb substantially the vacuolar transport of sporamin; moreover, whereas RAB-F2 proteins are genetically linked to the vacuolar Qa-SNARE VAM3/SYP22/SGR, ARA6/RAB-F1 is not (Ebine et al., 2011). In fact, the mutant phenotype of VAM3/SYP22/SGR was almost completely suppressed by the loss-of-function mutation of ARA6/RAB-F1 (Ebine et al., 2011), indicating the counteracting role of ARA6/RAB-F1 in vacuolar trafficking mediated by VAM3/SYP22/SGR. Therefore, ARA6/RAB-F1 is unlikely involved in vacuolar traffic in Arabidopsis, in contrast to RAB-F2. Instead, ARA6/RAB-F1 was shown to modulate PEN1/SYP121-VAMP727-driven vesicle fusion at the PM, which was elicited by environmental stimuli such as salinity (Ebine et al., 2011). Thus, there are likely multiple types of MVBs with distinct functions, although it is entirely unclear how they might originate. These three RAB-F class proteins are activated by the same RAB-GEF, VPS9a, in vitro (Goh et al., 2007).
The in vivo situation might be more complex since the $v p s 9 a$ mutant phenotype is suppressed by the overexpression of the GTP-locked form of ARA7/RAB-F2b, but not of ARA6/RAB-F1 (Goh et al., 2007; Ebine et al., 2011). In the tobacco epidermis, however, overexpression of VPS9a titrated out the negative effect of the nucleotide-free ARA6/RAB-F1, but not of RHA1/RABF2a (Bottanelli et al., 2011b). Thus, further analysis is required to understand precisely the biological functions of these RAB-F GTPases and their regulator, VPS9a.

$\mathrm{RAB}-\mathrm{H}$ related to mammalian Rab6 was demonstrated to rescue the yeast $y p t 6$ mutant, revealing its potential role in the retrograde trafficking from endosomes to the Golgi stacks (Bednarek et al., 1994; Johansen et al., 2009), but this was not clearly addressed.

Rice Rab7 belonging to the RAB-G subclass localizes at the tonoplast in Arabidopsis transient assays, consistent with its proposed involvement in vacuolar fusion (Nahm et al., 2003). By analogy, the overexpression of the nucleotide-free Arabidopsis Rab7 inhibits vacuolar targeting in tobacco epidermis (Bottanelli et al., 2011a). Rice prenylated Rab acceptor, OsPRA1 was shown to affect the fusion of PVCs/MVBs with the vacuole by interacting with both VAM3/SYP22/SGR and OsRAB7 (Heo et al., 2010).

\section{MEMBRANE FUSION BY SNARE COMPLEXES AND REGULATORY SM PROTEINS}

Membrane-anchored SNARE proteins form complexes that mediate membrane fusion, e.g., between a transport vesicle and its target membrane. Based on the analysis of yeast and mammalian SNARE complexes, each SNARE complex comprises a helical bundles of four SNARE domains (R, Qa, Qb, and Qc) that are contributed by one R-SNARE protein on the vesicle and two or three Q-SNARE (Qa, Qbc or Qa, Qb, and Qc) proteins on the target membrane (Fasshauer et al., 1998). The Arabidopsis genome encodes 54 SNARE proteins that grouped into $18 \mathrm{Qa}-$, 11 Qb-, 8 Qc-, and 14 R-SNAREs (Uemura et al., 2004). To date, however, only a few SNARE complexes have been characterized. SNARE complexes comprising SYP4/TLG2 (Qa = syntaxin), VTI1 (Qb), SYP61/OSM1 (Qc), and an unknown VAMP (RSNARE) protein mediate the fusion of PVC/MVB-derived vesicles at the TGN (Sanderfoot et al., 2001; Uemura et al., 2004). The SYP2 syntaxin family includes two members, PEP12/SYP21 and VAM3/SYP22/SGR, that differ in subcellular location, PVC/MVB vs. vacuole, but nonetheless are functionally redundant in vacuolar trafficking (Foresti et al., 2006; Tyrrell et al., 2007; Shirakawa et al., 2010; Uemura et al., 2010). However, RAB-F2 GTPases are genetically linked to VAM3/SYP22/SGR, but not to PEP12/SYP21 (Ebine et al., 2011). Furthermore, the SNARE complex comprising VAM3/SYP22/SGR (Qa), ZIG/VTI11 (Qb), SYP51 (Qc), and VAMP727 (R-SNARE) protein is involved in vacuolar traffic, seed maturation, vacuole biogenesis, and also in shoot gravitropism (Sanderfoot et al., 1999; Yano et al., 2003). ZIG/VTI11 can substitute for VTI12, which is related to PSV trafficking, but not vice versa (Sanmartín et al., 2007).

Syntaxins (Qa-SNARE proteins) of the SYP1 family are preferentially located at the PM except for KNOLLE/SYP111, which is specifically targeted to the plane of cell division (Lauber et al., 1997; Uemura et al., 2004; Enami et al., 2009; Reichardt et al., 2011). 
Interestingly, the closest KNOLLE homolog, SYP112, behaves like KNOLLE when expressed from the KNOLLE promoter, although SYP112 seems to have no function of its own (Müller et al., 2003). Other SYP1 family members such as SYP124, SYP125, and SYP131 are exclusively expressed in pollen and SYP123 is preferentially expressed in root hair cells (Enami et al., 2009; Silva et al., 2010). Overexpression of cytosolic fragments lacking the hydrophobic tail anchor of the PM-localized syntaxins PEN1/SYP121 and SYP122 and Qc-SNARE SYP71, which localizes at both the PM and the ER, were shown to suppress secretion of secGFP (Geelen et al., 2002; Tyrrell et al., 2007; Suwastika et al., 2008), but not of the chimeric protein secGFP-PMEI1 (De Caroli et al., 2011). Thus these findings suggest that there might be differentially regulated fusion mechanisms at the PM. It should be noted that the dominantnegative effect of the cytosolic fragment of PEN1/SYP121 is caused by titrating out SNARE interaction partners such as SNAP33, which possibly also form complexes with other SYP1 syntaxins (see below). PM-resident PEN1/SYP121 (Qa) confers non-host resistance to Arabidopsis against powdery mildew, forming SNARE complexes with SNAP33 (Qbc) and VAMP721 or VAMP722 (RSNAREs; Collins et al., 2003; Assaad et al., 2004; Kwon et al., 2008). PEN1/SYP121 and its close homolog SYP122 have some overlapping function in plant growth but SYP122 cannot substitute for PEN1/SYP121 in innate immunity (Assaad et al., 2004). PEN1/SYP121 interacts also with a $\mathrm{K}^{+}$-channel in stomatal closure (Grefen et al., 2010; Eisenach et al., 2011) and its ABA-related tobacco ortholog, NtSyr1/NtSYP121 is involved in vesicle trafficking to the PM (Geelen et al., 2002). SYP132 is involved in nodule symbiosis in Medicago and plant resistance against bacteria in tobacco (Catalano et al., 2007; Kalde et al., 2007). SYP132 was recently shown also to suppress the knolle mutant phenotype when expressed from the KNOLLE promoter (Reichardt et al., 2011), which is consistent with the accumulation of SYP132 at the cell plate in addition to its ubiquitous occurrence at the PM (Enami et al., 2009).

One of three SNAP25-orthologs, SNAP33 (Qbc-SNARE) promiscuously interacts with KNOLLE/SYP111 and PEN1/SYP121 (Heese et al., 2001; Collins et al., 2003; Kwon et al., 2008). Although snap33 mutant seedlings display some incomplete cell walls, they only die later because of necrotic lesions (Heese et al., 2001). Interestingly, the plant-specific Qb-SNARE, NPSN11 also interacts with KNOLLE/SYP111 (Zheng et al., 2002). However, the composition of KNOLLE-containing SNARE complexes is still unknown. Three out of 14 VAMPs (R-SNAREs) in Arabidopsis have been functionally studied; VAMP721 and VAMP722 are functionally redundant R-SNAREs of PEN1/SYP121 SNARE complexes and are essential for plant development (Kwon et al., 2008). VAMP727 locating at the subpopulation of PVCs/MVBs in the vicinity of the tonoplast plays a role in the transport of storage protein and in the biogenesis of the PSV (Ebine et al., 2008). Additionally, VAMP727 also

\section{REFERENCES}

Abas, L., Benjamins, R., Malenica, N., Paciorek, T., Wisniewska, J., Moulinier-Anzola, J. C., Sieberer, T., Friml, J., and Luschnig, C. (2006). Intracellular trafficking and proteolysis of the Arabidopsis auxin-

interacts with the Qa-SNARE PEN1/SYP121 at the PM, possibly stimulated by ARA6/RAB-F1 (Ebine et al., 2011).

Sec1/Munc18 (SM) family proteins confer specificity to membrane fusion by embracing monomeric syntaxins or assembled SNARE complexes (reviewed in Südhof and Rothman, 2009). The Arabidopsis genome has six members of SM proteins: SLY1, VPS45, VPS33, and three Sec1p homologs. VPS45 interacts with the SNARE complex of SYP41/SYP61/VTI12 at the TGN/EE and is involved in vacuolar trafficking (Zouhar et al., 2009). VPS33 is located at the tonoplast and PVCs/MVBs, and was proposed to be a member of the AtC-VPS complex that also comprises VCL1 and VPS11 (Rojo et al., 2003). Thus, VPS33 might be involved in vacuolar biogenesis and homotypic membrane fusion. KEULE is the only member of Secl homologs that has been functionally characterized in Arabidopsis. KEULE is required for cell-plate formation, interacting with KNOLLE/SYP111 genetically and biochemically (Waizenegger et al., 2000; Assaad et al., 2001). Additionally, KEULE might also act in root hair development, but independently of KNOLLE/SYP111, as suggested by abnormal root hair development in keule mutant seedlings (Assaad et al., 2001).

\section{PERSPECTIVES}

Although substantial progress in the analysis of plant membrane traffic has been achieved in recent years, there are still a number of serious open questions that we need to address in order to fully comprehend regulatory mechanisms underlying post-Golgi trafficking. First of all, we do not know how post-Golgi compartments originate and how they are established and maintained. More specifically, the organization of endosomes needs to be thoroughly analyzed ultrastructurally to clarify whether the diverse functions attributed to "endosomes" are different aspects of the same structure or rather features of specific and distinct compartments. This might also be important for the distinguishing between models for the origin of specific compartments, e.g., MVB maturation. It is also obvious that we need additional specific, both soluble and membrane-bound, cargo markers for each traffic destination for live imaging of trafficking pathways. All this should be combined with the genetic tools available in Arabidopsis, which have not been exploited fully and systematically to analyze regulatory mechanisms in membrane traffic. Furthermore, the crucial role of membrane lipids in post-Golgi traffic as well as raft-mediated endocytosis (Men et al., 2008; Kale et al., 2010; Markham et al., 2011) needs to be addressed in more detail.

\section{ACKNOWLEDGMENTS}

We thank Sandra Richter for critical reading of the manuscript. This work was funded by the DFG grant Ju179/15-1 within the framework of the Arabidopsis Functional Genomics Network (AFGN).

vacuolar sorting receptor AtELP is involved in transport of $\mathrm{NH}(2)$ terminal propeptide-containing vacuolar proteins in Arabidopsis thaliana. J. Cell Biol. 149, 1335-1344. Anders, N., and Jürgens, G. (2008). Large ARF guanine nucleotide exchange factors in membrane trafficking. Cell. Mol. Life Sci. 65, 3433-3445.

Assaad, F. F., Huet, Y., Mayer, U., and Jürgens, G. (2001). The cytokinesis gene KEULE encodes a Secl protein that binds the 
syntaxin KNOLLE. J. Cell Biol. 152, 531-543.

Assaad, F. F., Qiu, J. L., Youngs, H., Ehrhardt, D., Zimmerli, L., Kalde, M., Wanner, G., Peck, S. C., Edwards, H., Ramonell, K., Somerville, C. R., and Thordal-Christensen, $\mathrm{H}$. (2004). The PEN1 syntaxin defines a novel cellular compartment upon fungal attack and is required for the timely assembly of papillae. Mol. Biol. Cell 15, 5118-5129.

Banbury, D. N., Oakley, J. D., Sessions, R. B., and Banting, G. (2003). Tyrphostin A23 inhibits internalization of the transferrin receptor by perturbing the interaction between tyrosine motifs and the medium chain subunit of the AP-2 adaptor complex. J. Biol. Chem. 278, 12022-12028.

Barberon, M., Zelazny, E., Robert, S., Conéjéro, G., Curie, C., Friml, J., and Vert, G. (2011). Monoubiquitindependent endocytosis of the ironregulated transporter 1 (IRT1) transporter controls iron uptake in plants. Proc. Natl. Acad. Sci. U.S.A. 108, E450-E458.

Barth, M., and Holstein, S. E. (2004). Identification and functional characterization of Arabidopsis AP180, a binding partner of plant alphaCadaptin. J. Cell Sci. 117, 2051-2062.

Bassham, D. C., Sanderfoot, A. A., Kovaleva, V., Zheng, H., and Raikhel, N. V. (2000). AtVPS45 complex formation at the trans-Golgi network. Mol. Biol. Cell 11, 2251-2265.

Batoko, H., Zheng, H. Q., Hawes, C., and Moore, I. (2000). A Rab1 GTPase is required for transport between the endoplasmic reticulum and Golgi apparatus and for normal Golgi movement in plants. Plant Cell 12, 2201-2217.

Bednarek, S. Y., Reynolds, T. L., Schroeder, M., Grabowski, R., Hengst, L., Gallwitz, D., and Raikhel, N. V. (1994). A small GTP-binding protein from Arabidopsis thaliana functionally complements the yeast YPT6 null mutant. Plant Physiol. 104, 591-196.

Boehm, M., and Bonifacino, J. S. (2001). Adaptins: the final recount. Mol. Biol. Cell 12, 2907-2920.

Böhlenius, H., Mørch, S. M., Godfrey, D., Nielsen, M. E., and Thordal-Christensen, H. (2010). The multivesicular body-localized GTPase ARFAlb/1c is important for callose deposition and ROR2 syntaxin-dependent preinvasive basal defense in barley. Plant Cell 22, 3831-3844.

Bolte, S., Brown, S., and SatiatJeunemaitre, B. (2004). The
N-myristoylated Rab-GTPase mRabmc is involved in post-Golgi trafficking events to the lytic vacuole in plant cells. J. Cell. Sci. 117, 943-954.

Borgese, N., and Fasana, E. (2011). Targeting pathways of C-tail-anchored proteins. Biochim. Biophys. Acta 1808, 937-946.

Bottanelli, F., Foresti, O., Hanton, S., and Denecke, J. (2011a). Vacuolar transport in tobacco leaf epidermis cells involves a single route for soluble cargo and multiple routes for membrane cargo. Plant Cell 23, 3007-3025.

Bottanelli, F., Gershlick, D. C., and Denecke, J. (2011b). Evidence for sequential action of Rab5 and Rab7 GTPases in prevacuolar organelle partitioning. Traffic. doi: 10.1111/j.1600-0854.2011.01303.x

Brandizzi, F., Frangne, N., Marc-Martin, S., Hawes, C., Neuhaus, J. M., and Paris, N. (2002). The destination for single-pass membrane proteins is influenced markedly by the length of the hydrophobic domain. Plant Cell 14, 1077-1092.

Cai, Y., Jia, T., Lam, S. K., Ding, Y., Gao, C., San, M. W., Pimpl, P., and Jiang, L. (2011). Multiple cytosolic and transmembrane determinants are required for the trafficking of SCAMP1 via an ER-Golgi-TGN-PM pathway. Plant J. 65, 882-896.

Camacho, L., Smertenko, A. P., PérezGómez, J., Hussey, P. J., and Moore, I. (2009). Arabidopsis Rab-E GTPases exhibit a novel interaction with a plasma-membrane phosphatidylinositol-4-phosphate 5-kinase. J. Cell. Sci. 122, 4383-4392. Catalano, C. M., Czymmek, K. J., Gann, J. G., and Sherrier, D. J. (2007). Medicago truncatula syntaxin SYP132 defines the symbiosome membrane and infection droplet membrane in root nodules. Planta 225, 541-550.

Chow, C. M., Neto, H., Foucart, C., and Moore, I. (2008). Rab-A2 and RabA3 GTPases define a trans-Golgi endosomal membrane domain in Arabidopsis that contributes substantially to the cell plate. Plant Cell 20, 101-123.

Collins, N. C., Thordal-Christensen, H., Lipka, V., Bau, S., Kombrink, E., Qiu, J. L., Hückelhoven, R., Stein, M., Freialdenhoven, A., Somerville, S. C., and Schulze-Lefert, P. (2003). SNARE-protein-mediated disease resistance at the plant cell wall. Nature 425, 973-977.

daSilva, L. L., Foresti, O., and Denecke, J. (2006). Targeting of the plant vacuolar sorting receptor BP80 is dependent on multiple sorting signals in the cytosolic tail. Plant Cell 18, 1477-1497.

daSilva, L. L., Taylor, J. P., Hadlington, J. L., Hanton, S. L., Snowden, C. J., Fox, S. J., Foresti, O., Brandizzi, F., and Denecke, J. (2005). Receptor salvage from the prevacuolar compartment is essential for efficient vacuolar protein targeting. Plant Cell 17, 132-148.

De Caroli, M., Lenucci, M. S., Di Sansebastiano, G. P., Dalessandro, G., De Lorenzo, G., and Piro, G. (2011) Protein trafficking to the cell wall occurs through mechanisms distinguishable from default sorting in tobacco. Plant J. 65, 295-308.

de Graaf, B. H., Cheung, A. Y. Andreyeva, T., Levasseur, K., Kieliszewski, M., and Wu, H. M. (2005). Rab11 GTPase-regulated membrane trafficking is crucial for tip-focused pollen tube growth in tobacco. Plant Cell 17, 2564-2579.

Denecke, J., Botterman, J., and Deblaere, R. (1991). Protein secretion in plant cells can occur via a default pathway. Plant Cell 2, 51-59.

Dettmer, J., Hong-Hermesdorf, A., Stierhof, Y. D., and Schumacher, K. (2006). Vacuolar H+-ATPase activity is required for endocytic and secretory trafficking in Arabidopsis. Plant Cell 18, 715-730.

Dhonukshe, P., Aniento, F., Hwang, I., Robinson, D. G., Mravec, J., Stierhof, Y. D., and Friml, J. (2007). Clathrinmediated constitutive endocytosis of PIN auxin efflux carriers in Arabidopsis. Curr. Biol. 17, 520-527.

Dhonukshe, P., Baluska, F., Schlicht, M., Hlavacka, A., Samaj, J., Friml, J., and Gadella, T. W. J. (2006). Endocytosis of cell surface material mediates cell plate formation during plant cytokinesis. Dev. Cell 10, 137-150.

Dhonukshe, P., Huang, F., GalvanAmpudia, C. S., Mähönen, A. P., Kleine-Vehn, J., Xu, J., Quint, A., Prasad, K., Friml, J., Scheres, B. and Offringa, R. (2010). Plasma membrane-bound AGC3 kinases phosphorylate PIN auxin carriers at TPRXS(N/S) motifs to direct apical PIN recycling. Development 137 , 3245-3255.

Dhonukshe, P., Tanaka, H., Goh, T. Ebine, K., Mähönen, A. P., Prasad, K., Blilou, I., Geldner, N., Xu, J., Uemura, T., Chory, J., Ueda, T., Nakano, A., Scheres, B., and Friml, J. (2008). Generation of cell polarity in plants links endocytosis, auxin distribution and cell fate decisions. Nature 456, 962-966.

Di Sansebastiano, G. P., Paris, N. Marc-Martin, S., and Neuhaus, J.
M. (1998). Specific accumulation of GFP in a non-acidic vacuolar compartment via a C-terminal propeptide-mediated sorting pathway. Plant J. 15, 449-457.

Ding, Z., Galván-Ampudia, C. S., Demarsy, E., Langowski, L., KleineVehn, J., Fan, Y., Morita, M. T., Tasaka, M., Fankhauser, C., Offringa, R., and Friml, J. (2011). Lightmediated polarization of the PIN3 auxin transporter for the phototropic response in Arabidopsis. Nat. Cell Biol. 13, 447-452.

Drakakaki, G., Van De Ven, W., Pan, S., Miao, Y., Wang, J., Keinath, N. K., Weatherly, B., Jiang, L., Schumacher, K., Hicks, G., and Raikhel, N. (2011). Isolation and proteomic analysis of the SYP61 compartment reveal its role in exocytic trafficking in Arabidopsis. Cell Res. doi:10.1038/cr.2011.129

Ebine, K., Fujimoto, M., Okatani, Y., Nishiyama, T., Goh, T., Ito, E., Dainobu, T., Nishitani, A., Uemura, T., Sato, M. H., Thordal-Christensen, H., Tsutsumi, N., Nakano, A., and Ueda, T. (2011). A membrane trafficking pathway regulated by the plant-specific RAB GTPase ARA6. Nat. Cell Biol. 13, 853-859.

Ebine, K., Okatani, Y., Uemura, T., Goh, T., Shoda, K., Niihama, M., Morita, M. T., Spitzer, C., Otegui, M. S., Nakano, A., and Ueda, T. (2008). A SNARE complex unique to seed plants is required for protein storage vacuole biogenesis and seed development of Arabidopsis thaliana. Plant Cell 20, 3006-3021.

Eisenach, C., Chen, Z. H., Grefen, C. and Blatt, M. R. (2011). The trafficking protein SYP121 of Arabidopsis connects programmed stomatal closure and $\mathrm{K}(+)$ channel activity with vegetative growth. Plant J. doi: 10.1111/j.1365-313X.2011.04786.x

Emans, N., Zimmermann, S., and Fischer, R. (2002). Uptake of a fluorescent marker in plant cells is sensitive to brefeldin A and wortmannin. Plant Cell 14, 71-86.

Enami, K., Ichikawa, M., Uemura, T., Kutsuna, N., Hasezawa, S., Nakagawa, T., Nakano, A., and Sato, M. H. (2009). Differential expression control and polarized distribution of plasma membrane-resident SYP1 SNAREs in Arabidopsis thaliana. Plant Cell Physiol. 50, 280-289.

Fasshauer, D., Sutton, R. B., Brunger, A. T., and Jahn, R. (1998). Conserved structural features of the synaptic fusion complex: SNARE proteins reclassified as Q- and R-SNAREs. Proc. Natl. Acad. Sci. U.S.A. 95, 15781-15786. 
Feraru, E., Paciorek, T., Feraru, M. I., Zwiewka, M., De Groodt, R., De Rycke, R., Kleine-Vehn, J., and Friml, J. (2010). The AP-3 $\beta$ adaptin mediates the biogenesis and function of lytic vacuoles in Arabidopsis. Plant Cell 22, 2812-2824.

Foresti, O., daSilva, L. L., and Denecke, J. (2006). Overexpression of the Arabidopsis syntaxin PEP12/SYP21 inhibits transport from the prevacuolar compartment to the lytic vacuole in vivo. Plant Cell 18, 2275-2293.

Foresti, O., Gershlick, D. C., Bottanelli, F., Hummel, E., Hawes, C., and Denecke, J. (2010). A recyclingdefective vacuolar sorting receptor reveals an intermediate compartment situated between prevacuoles and vacuoles in tobacco. Plant Cell 22, 3992-4008.

Frigerio, L., de Virgilio, M., Prada, A., Faoro, F., and Vitale, A. (1998). Sorting of phaseolin to the vacuole is saturable and requires a short C-terminal peptide. Plant Cell 10,1031-1042.

Frigerio, L., Hinz, G., and Robinson, D. G. (2008). Multiple vacuoles in plant cells: rule or exception? Traffic 9, 1564-1570.

Friml, J., Wisniewska, J., Benková, E., Mendgen, K., and Palme, K. (2002). Lateral relocation of auxin efflux regulator PIN3 mediates tropism in Arabidopsis. Nature 415, 806-809.

Fujimoto, M., Arimura, S., Ueda, T., Takanashi, H., Hayashi, Y., Nakano, A., and Tsutsumi, N. (2010). Arabidopsis dynamin-related proteins DRP2B and DRP1A participate together in clathrin-coated vesicle formation during endocytosis. Proc. Natl. Acad. Sci. U.S.A. 107, 6094-6099.

Geelen, D., Leyman, B., Batoko, H., Di Sansebastiano, G. P., Moore, I., and Blatt, M. R. (2002). The abscisic acid-related SNARE homolog NtSyr 1 contributes to secretion and growth: evidence from competition with its cytosolic domain. Plant Cell 14, 387-406.

Geldner, N., Anders, N., Wolters, H., Keicher, J., Kornberger, W., Muller, P., Delbarre, A., Ueda, T., Nakano, A., and Jürgens, G. (2003). The Arabidopsis GNOM ARF-GEF mediates endosomal recycling, auxin transport, and auxin-dependent plant growth. Cell 112, 219-230.

Geldner, N., Dénervaud-Tendon, V., Hyman, D. L., Mayer, U., Stierhof, Y. D., and Chory, J. (2009). Rapid, combinatorial analysis of membrane compartments in intact plants with a multicolor marker set. Plant J. 59, 169-178.
Geldner, N., Hyman, D. L., Wang, X., Schumacher, K., and Chory, J. (2007). Endosomal signaling of plant steroid receptor kinase BRI1. Genes Dev. 21, 1598-1602.

Geldner, N., and Jürgens, G. (2006). Endocytosis in signalling and development. Curr. Opin. Plant Biol. 9, 589-594.

Goh, T., Uchida, W., Arakawa, S., Ito, E., Dainobu, T., Ebine, K., Takeuchi, M., Sato, K., Ueda, T., and Nakano, A. (2007). VPS9a, the common activator for two distinct types of Rab5 GTPases, is essential for the development of Arabidopsis thaliana. Plant Cell 19, 3504-3515.

Grefen, C., Chen, Z., Honsbein, A., Donald, N., Hills, A., and Blatt, M. R. (2010). A novel motif essential for SNARE interaction with the $\mathrm{K}(+)$ channel $\mathrm{KCl}$ and channel gating in Arabidopsis. Plant Cell 22, 3076-3092.

Happel, N., Honing, S., Neuhaus, J. M., Paris, N., Robinson, D. G., and Holstein, S. E. (2004). Arabidopsis mu A-adaptin interacts with the tyrosine motif of the vacuolar sorting receptor VSR-PS1. Plant J. 37, 678-693.

Hara-Nishimura, I. I., Shimada, T., Hatano, K., Takeuchi, Y., and Nishimura, M. (1998). Transport of storage proteins to protein storage vacuoles is mediated by large precursor-accumulating vesicles. Plant Cell 10, 825-836.

Heese, M., Gansel, X., Sticher, L., Wick, P., Grebe, M., Granier, F., and Jürgens, G. (2001). Functional characterization of the KNOLLEinteracting t-SNARE AtSNAP33 and its role in plant cytokinesis. J. Cell Biol. 155, 239-249.

Heo, J. B., Bang, W. Y., Kim, S. W., Hwang, S. M., Son, Y. S., Im, C. H., Acharya, B. R., Kim, C. W., Kim, S. W., Lee, B. H., and Bahk, J. D. (2010). OsPRAl plays a significant role in targeting of OsRab7 into the tonoplast via the prevacuolar compartment during vacuolar trafficking in plant cells. Planta 232, 861-871.

Hillmer, S., Movafeghi, A., Robinson, D. G., and Hinz, G. (2001). Vacuolar storage proteins are sorted in the ciscisternae of the pea cotyledon Golgi apparatus. J. Cell Biol. 152, 41-50.

Hinz, G., Colanesi, S., Hillmer, S., Rogers, J. C., and Robinson, D. G. (2007). Localization of vacuolar transport receptors and cargo proteins in the Golgi apparatus of developing Arabidopsis embryos. Traffic 8, 1452-1464.

Hinz, G., Hillmer, S., Baumer, M., and Hohl, I. I. (1999). Vacuolar storage proteins and the putative vacuolar sorting receptor BP-80 exit the Golgi apparatus of developing pea cotyledons in different transport vesicles. Plant Cell 11, 1509-1524.

Hirst, J., D Barlow, L., Francisco, G. C., Sahlender, D. A., Seaman, M. N., Dacks, J. B., and Robinson, M. S. (2011). The fifth adaptor protein complex. PLoS Biol. 9, e1001170. doi:10.1371/journal.pbio.1001170

Höfte, H., Hubbard, L., Reizer, J. Ludevid, D., Herman, E. M., and Chrispeels, M. J. (1992). Vegetative and seed-specific forms of tonoplast intrinsic protein in the vacuolar membrane of Arabidopsis thaliana. Plant Physiol. 99, 561-570.

Hohl, I., Robinson, D. G., Chrispeels, M. J., and Hinz, G. (1996). Transport of storage proteins to the vacuole is mediated by vesicles without a clathrin coat. J. Cell. Sci. 109, 2539-2550.

Hunter, P. R., Craddock, C. P., Di Benedetto, S., Roberts, L. M., and Frigerio, L. (2007). Fluorescent reporter proteins for the tonoplast and the vacuolar lumen identify a single vacuolar compartment in Arabidopsis cells. Plant Physiol. 145, 1371-1382.

Ito, E., Fujimoto, M., Ebine, K., Uemura, T., Ueda, T., and Nakano, A. (2011). Dynamic behavior of clathrin in Arabidopsis thaliana unveiled by live imaging. Plant J. doi:10.1111/j.1365-313X.2011 04782.X

Jaillais, Y., Fobis-Loisy, I., Miège, C. and Gaude, T. (2008). Evidence for a sorting endosome in Arabidopsis root cells. Plant J. 53, 237-247.

Jaillais, Y., Fobis-Loisy, I., Miège, C., Rollin, C., and Gaude, T. (2006). AtSNX1 defines an endosome for auxin-carrier trafficking in Arabidopsis. Nature 443, 106-109.

Jaillais, Y., Santambrogio, M., Rozier, F., Fobis-Loisy, I., Miège, C., and Gaude, T. (2007). The retromer protein VPS29 links cell polarity and organ initiation in plants. Cell 130, 1057-1070.

Jia, D. J., Cao, X., Wang, W., Tan, X. Y., Zhang, X. Q., Chen, L. Q., and Ye, D. (2009). GNOM-LIKE 2, encoding an adenosine diphosphate-ribosylation factor-guanine nucleotide exchange factor protein homologous to GNOM and GNL1, is essential for pollen germination in Arabidopsis. J. Integr. Plant Biol. 51, 762-773.

Jiang, L., Phillips, T. E., Rogers, S. W. and Rogers, J. C. (2000). Biogenesis of the protein storage vacuole crystalloid. J. Cell Biol. 150, 755-770.

Jin, J. B., Kim, Y. A., Kim, S. J., Lee, S. H., Kim, D. H., Cheong, G. W., and
Hwang, I. (2001). A new dynaminlike protein, ADL6, is involved in trafficking from the trans-Golgi network to the central vacuole in Arabidopsis. Plant Cell 13, 1511-1526.

Johansen, J. N., Chow, C. M., Moore, I., and Hawes, C. (2009). AtRAB-H1b and AtRAB-H1c GTPases, homologues of the yeast Ypt6, target reporter proteins to the Golgi when expressed in Nicotiana tabacum and Arabidopsis thaliana. J. Exp. Bot. 60, 3179-3193.

Jung, C., Lee, G. J., Jang, M., Lee, M., Lee, J., Kang, H., Sohn, E. J., and Hwang, I. (2011). Identification of sorting motifs of At $\beta$ Fruct 4 for trafficking from the ER to the vacuole through the Golgi and PVC. Traffic 12, 1774-1792.

Jürgens, G. (2005). Plant cytokinesis: fission by fusion. Trends Cell Biol. 15, 277-283.

Jürgens, G., and Geldner, N. (2002). Protein secretion in plants: from the trans-Golgi network to the outer space. Traffic 3, 605-611.

Kalde, M., Nühse, T. S., Findlay, K., and Peck, S. C. (2007). The syntaxin SYP132 contributes to plant resistance against bacteria and secretion of pathogenesis-related protein 1. Proc. Natl. Acad. Sci. U.S.A. 104, 11850-11855.

Kale, S. D., Gu, B., Capelluto, D. G., Dou, D., Feldman, E., Rumore, A., Arredondo, F. D., Hanlon, R., Fudal, I., Rouxel, T., Lawrence, C. B., Shan, W., and Tyler, B. M. (2010). External lipid PI3P mediates entry of eukaryotic pathogen effectors into plant and animal host cells. Cell 142, 284-295.

Kang, B. H., Nielsen, E., Preuss, M. L., Mastronarde, D., and Staehelin, L. A. (2011). Electron tomography of RabA4b- and PI- $4 \mathrm{~K} \beta 1$-labeled trans Golgi network compartments in Arabidopsis. Traffic 12, 313-329.

Kasai, K., Takano, J., Miwa, K., Toyoda, A., and Fujiwara, T. (2011). High boron-induced ubiquitination regulates vacuolar sorting of the BOR1 borate transporter in Arabidopsis thaliana. J. Biol. Chem. 286, 6175-6183.

Kim, H., Kang, H., Jang, M., Chang, H. H., Miao, Y., Jiang, L., and Hwang, I. (2010). Homomeric interaction of AtVSR1 is essential for its function as a vacuolar sorting receptor. Plant Physiol. 154, 1134-1148.

Kirsch, T., Paris, N., Butler, J. M., Beevers, L., and Rogers, J. C. (1994). Purification and initial characterization of a potential plant vacuolar targeting receptor. Proc. Natl. Acad. Sci. U.S.A. 91, 3403-3407. 
Kitakura, S., Vanneste, S., Robert, S., Löfke, C., Teichmann, T., Tanaka, H., and Friml, J. (2011). Clathrin mediates endocytosis and polar distribution of PIN auxin transporters in Arabidopsis. Plant Cell 23, 1920-1931.

Kleine-Vehn, J., Dhonukshe, P., Swarup, R., Bennett, M., and Friml, J. (2006). Subcellular trafficking of the Arabidopsis auxin influx carrier AUX1 uses a novel pathway distinct from PIN1. Plant Cell 18, 3171-3181.

Kleine-Vehn, J., Leitner, J., Zwiewka, M., Sauer, M., Abas, L., Luschnig, C., and Friml, J. (2008). Differential degradation of PIN2 auxin efflux carrier by retromer-dependent vacuolar targeting. Proc. Natl. Acad. Sci. U.S.A. 105, 17812-17817.

Koizumi, K., Naramoto, S., Sawa, S., Yahara, N., Ueda, T., Nakano, A., Sugiyama, M., and Fukuda, H. (2005). VAN3 ARF-GAP-mediated vesicle transport is involved in leaf vascular network formation. Development 132, 1699-1711.

Kwon, C., Neu, C., Pajonk, S., Yun, H. S., Lipka, U., Humphry, M., Bau, S., Straus, M., Kwaaitaal, M., Rampelt, H., El Kasmi, F., Jürgens, G., Parker, J., Panstruga, R., Lipka, V., and Schulze-Lefert, P. (2008). Cooption of a default secretory pathway for plant immune responses. Nature 451, 835-840.

Lam, B. C., Sage, T. L., Bianchi, F., and Blumwald, E. (2002). Regulation of ADL6 activity by its associated molecular network. Plant J. 31, 565-576.

Lam, S. K., Siu, C. L., Hillmer, S., Jang, S., An, G., Robinson, D. G., and Jiang, L. (2007). Rice SCAMP1 defines clathrin-coated, transGolgi-located tubular-vesicular structures as an early endosome in tobacco BY-2 cells. Plant Cell 19, 296-319.

Langowski, L., Ruzicka, K., Naramoto, S., Kleine-Vehn, J., and Friml, J. (2010). Trafficking to the outer polar domain defines the root-soil interface. Curr. Biol. 20, 904-908.

Lauber, M. H., Waizenegger, I., Steinmann, T., Schwarz, H., Mayer, U., Hwang, I., Lukowitz, W., and Jürgens, G. (1997). The Arabidopsis KNOLLE protein is a cytokinesisspecific syntaxin. J. Cell Biol. 139, 1485-1493.

Lee, G. J., Kim, H., Kang, H., Jang, M., Lee, D. W., Lee, S., and Hwang, I. (2007). EpsinR2 interacts with clathrin, adaptor protein-3, AtVTI12, and phosphatidylinositol3-phosphate. Implications for
EpsinR2 function in protein trafficking in plant cells. Plant Physiol. 143, 1561-1575

Lee, G. J., Sohn, E. J., Lee, M. H., and Hwang, I. (2004). The Arabidopsis rab5 homologs rhal and ara7 localize to the prevacuolar compartment. Plant Cell Physiol. 45, 1211-1220.

Li, R., Xiong, G., and Zhou, Y. (2010). Membrane trafficking mediated by OsDRP2B is specific for cellulose biosynthesis. Plant Signal. Behav. 5, 1483-1486.

Liljegren, S. J., Leslie, M. E., Darnielle, L., Lewis, M. W., Taylor, S. M., Luo, R., Geldner, N., Chory, J., Randazzo, P. A., Yanofsky, M. F., and Ecker, J. R. (2009). Regulation of membrane trafficking and organ separation by the NEVERSHED ARF-GAP protein. Development 136, 1909-1918.

Liu, S. H., Wong, M. L., Craik, C. S., and Brodsky, F. M. (1995). Regulation of clathrin assembly and trimerization defined using recombinant triskelion hubs. Cell 83, 257-267.

Lu, D., Lin, W., Gao, X., Wu, S., Cheng, C., Avila, J., Heese, A., Devarenne, T. P., He, P., and Shan, L. (2011). Direct ubiquitination of pattern recognition receptor FLS2 attenuates plant innate immunity. Science 332, 1439-1442.

Luzio, J. P., Gray, S. R., and Bright, N. A. (2010). Endosome-lysosome fusion. Biochem. Soc. Trans. 38, 1413-1416.

Markham, J. E., Molino, D., Gissot, L., Bellec, Y., Hématy, K., Marion, J., Belcram, K., Palauqui, J. C., Satiat-Jeunemaître, B., and Faure, J. D. (2011). Sphingolipids containing very-long-chain Fatty acids define a secretory pathway for specific polar plasma membrane protein targeting in Arabidopsis. Plant Cell 23, 2362-2378.

Marty, F. (1999). Plant vacuoles. Plant Cell 11, 587-600.

Matheson, L. A., Hanton, S. L., Rossi, M., Latijnhouwers, M., Stefano, G., Renna, L., and Brandizzi, F. (2007). Multiple roles of ADP-ribosylation factor 1 in plant cells include spatially regulated recruitment of coatomer and elements of the Golgi matrix. Plant Physiol. 43, 1615-1627.

Matheson, L. A., Suri, S. S., Hanton, S. L., Chatre, L., and Brandizzi, F. (2008). Correct targeting of plant ARF GTPases relies on distinct protein domains. Traffic 9, 103-120.

Men, S., Boutté, Y., Ikeda, Y., Li, X., Palme, K., Stierhof, Y. D., Hartmann, M. A., Moritz, T., and Grebe, M. (2008). Sterol-dependent endocytosis mediates post-cytokinetic acquisition of PIN2 auxin efflux carrier polarity. Nat. Cell Biol. 10, 237-244.
Miao, Y., Li, K. Y., Li, H. Y., Yao, X. and Jiang, L. (2008). The vacuolar transport of aleurain-GFP and $2 \mathrm{~S}$ albumin-GFP fusions is mediated by the same pre-vacuolar compartments in tobacco BY-2 and Arabidopsis suspension cultured cells. Plant J. 56, 824-839.

Michniewicz, M., Zago, M. K., Abas, L., Weijers, D., Schweighofer, A., Meskiene, I., Heisler, M. G., Ohno, C., Zhang, J., Huang, F., Schwab, R., Weigel, D., Meyerowitz, E. M., Luschnig, C., Offringa, R., and Friml, J. (2007). Antagonistic regulation of PIN phosphorylation by PP2A and PINOID directs auxin flux. Cell 130, 1044-1056.

Min, M. K., Kim, S. J., Miao, Y., Shin, J., Jiang, L., and Hwang, I. (2007). Overexpression of Arabidopsis AGD7 causes relocation of Golgilocalized proteins to the endoplasmic reticulum and inhibits protein trafficking in plant cells. Plant Physiol. 143, 1601-1614.

Miwa, K., Takano, J., Omori, H., Seki, M., Shinozaki, K., and Fujiwara, T. (2007). Plants tolerant of high boron levels. Science 318, 1417.

Moscatelli, A., Ciampolini, F. Rodighiero, S., Onelli, E., Cresti, M., Santo, N., and Idilli, A. (2007). Distinct endocytic pathways identified in tobacco pollen tubes using charged nanogold. J. Cell Sci. 120, 3804-3819.

Mravec, J., Petrášek, J., Li, N., Boeren, S., Karlova, R., Kitakura, S., Parezová, M., Naramoto, S., Nodzynski, T. Dhonukshe, P., Bednarek, S. Y., Zažímalová, E., De Vries, S., and Friml, J. (2011). Cell plate restricted association of DRP1A and PIN proteins is required for cell polarity establishment in Arabidopsis. Curr. Biol. 21, 1055-1060.

Müller, I., Wagner, W., Völker, A., Schellmann, S., Nacry, P., Küttner, F., Schwarz-Sommer, Z., Mayer, U., and Jürgens, G. (2003). Syntaxin specificity of cytokinesis in Arabidopsis. Nat. Cell Biol. 5, 531-534.

Nahm, M. Y., Kim, S. W., Yun, D. Lee, S. Y., Cho, M. J., and Bahk, J. D. (2003). Molecular and biochemical analyses of OsRab7, a rice Rab7 homolog. Plant Cell Physiol. 44, 1341-1349.

Naramoto, S., Kleine-Vehn, J., Robert, S., Fujimoto, M., Dainobu, T. Paciorek, T., Ueda, T., Nakano, A., Van Montagu, M. C., Fukuda, H., and Friml, J. (2010). ADPribosylation factor machinery mediates endocytosis in plant cells. Proc. Natl. Acad. Sci. U.S.A. 107, 21890-21895.
Nielsen, M., Albrethsen, J., Larsen, F. H., and Skriver, K. (2006). The Arabidopsis ADP-ribosylation factor (ARF) and ARF-like (ARL) system and its regulation by BIG2, a large ARF-GEF. Plant Sci. 171, 707-717.

Niemes, S., Labs, M., Scheuring, D., Krueger, F., Langhans, M., Jesenofsky, B., Robinson, D. G., and Pimpl, P. (2011). Sorting of plant vacuolar proteins is initiated in the ER. Plant J. 62, 601-614.

Niemes, S., Langhans, M., Viotti, C., Scheuring, D., San Wan Yan, M., Jiang, L., Hillmer, S., Robinson, D. G., and Pimpl, P. (2010). Retromer recycles vacuolar sorting receptors from the trans-Golgi network. Plant J. 61, 107-121.

Niihama, M., Takemoto, N., Hashiguchi, Y., Tasaka, M., and Morita, M. T. (2009). ZIP genes encode proteins involved in membrane trafficking of the TGN-PVC/vacuoles. Plant Cell Physiol. 50, 2057-2068.

Nomura, K., Debroy, S., Lee, Y. H., Pumplin, N., Jones, J., and He, S. Y. (2006). A bacterial virulence protein suppresses host innate immunity to cause plant disease. Science 313, 220-223.

Olbrich, A., Hillmer, S., Hinz, G. Oliviusson, P., and Robinson, D. G. (2007). Newly formed vacuoles in root meristems of barley and pea seedlings have characteristics of both protein storage and lytic vacuoles. Plant Physiol. 145, 1383-1394.

Oliviusson, P., Heinzerling, O., Hillmer, S., Hinz, G., Tse, Y. C., Jiang, L., and Robinson, D. G. (2006). Plant retromer, localized to the prevacuolar compartment and microvesicles in Arabidopsis, may interact with vacuolar sorting receptors. Plant Cell 18, 1239-1252.

Onelli, E., Prescianotto-Baschong, C., Caccianiga, M., and Moscatelli, A. (2008). Clathrin-dependent and independent endocytic pathways in tobacco protoplasts revealed by labelling with charged nanogold. J. Exp. Bot. 59, 3051-3068.

Ortiz-Zapater, E., Soriano-Ortega, E., Marcote, M. J., Ortiz-Masiá, D., and Aniento, F. (2006). Trafficking of the human transferrin receptor in plant cells: effects of tyrphostin A23 and brefeldin A. Plant J. 48, 757-770.

Otegui, M. S., Herder, R., Schulze, J., Jung, R., and Staehelin, L. A. (2006). The proteolytic processing of seed storage proteins in Arabidopsis embryo cells starts in the multivesicular bodies. Plant Cell 18 2567-2581. 
Otegui, M. S., Mastronarde, D. N., Kang, B. H., Bednarek, S. Y., and Staehelin, L. A. (2001). Three-dimensional analysis of syncytial-type cell plates during endosperm cellularization visualized by high resolution electron tomography. Plant Cell 13, 2033-2051.

Otegui, M. S., and Spitzer, C. (2008). Endosomal functions in plants. Traffic 9, 1589-1598.

Panikashvili, D., Savaldi-Goldstein, S., Mandel, T., Yifhar, T., Franke, R. B., Höfer, R., Schreiber, L., Chory, J., and Aharoni, A. (2007). The Arabidopsis DESPERADO/AtWBC11 transporter is required for cutin and wax secretion. Plant Physiol. 145, 1345-1360.

Paris, N., Stanley, C. M., Jones, R. L., and Rogers, J. C. (1996). Plant cells contain two functionally distinct vacuolar compartments. Cell 85, 563-572.

Park, J. H., Oufattolea, M., and Rogers, J. C. (2007). Golgi-mediated vacuolar sorting in plant cells: RMR proteins are sorting receptors for the protein aggregation/membrane internalization pathway. Plant Sci. 172, 728-745.

Park, M., Kim, S. J., Vitale, A., and Hwang, I. (2004). Identification of the protein storage vacuole and protein targeting to the vacuole in leaf cells of three plant species. Plant Physiol. 134, 625-639.

Park, M., Lee, D., Lee, G. J., and Hwang, I. (2005). AtRMR1 functions as a cargo receptor for protein trafficking to the protein storage vacuole. $J$. Cell Biol. 170, 757-767.

Pesacreta, T. C., and Lucas, W. J. (1984). Plasma membrane coat and a coated vesicle-associated reticulum of membranes: their structure and possible interrelationship in Chara corallina. J. Cell Biol. 98, 1537-1545.

Pimpl, P., Movafeghi, A., Coughlan, S., Denecke, J., Hillmer, S., and Robinson, D. G. (2000). In situ localization and in vitro induction of plant COPI-coated vesicles. Plant Cell 12, 2219-2236.

Poteryaev, D., Datta, S., Ackema, K., Zerial, M., and Spang, A. (2010). Identification of the switch in early-tolate endosome transition. Cell 141, 497-508.

Pourcher, M., Santambrogio, M., Thazar, N., Thierry, A. M., FobisLoisy, I., Miège, C., Jaillais, Y., and Gaude, T. (2010). Analyses of sorting nexins reveal distinct retromer-subcomplex functions in development and protein sorting in Arabidopsis thaliana. Plant Cell 22, 3980-3991.
Praefcke, G. J., and McMahon, H. T. (2004). The dynamin superfamily: universal membrane tubulation and fission molecules? Nat. Rev. Mol. Cell Biol. 5, 133-147.

Preuss, M. L., Schmitz, A. J., Thole, J. M., Bonner, H. K., Otegui, M. S., and Nielsen, E. (2006). A role for the RabA4b effector protein PI- $4 \mathrm{~K} \beta 1$ in polarized expansion of root hair cells in Arabidopsis thaliana. J. Cell Biol. 172, 991-998.

Preuss, M. L., Serna, J., Falbel, T. G., Bednarek, S. Y., and Nielsen, E. (2004). The Arabidopsis Rab GTPase RabA4b localizes to the tips of growing root hair cells. Plant Cell 16, 1589-1603.

Pucadyil, T. J., and Schmid, S. L. (2009). Conserved functions of membrane active GTPases in coated vesicle formation. Science 325, 1217-1220.

Qi, X., Kaneda, M., Chen, J., Geitmann, A., and Zheng, H. (2011). A specific role for Arabidopsis TRAPPII in post-Golgi trafficking that is crucial for cytokinesis and cell polarity. Plant J. 68, 234-248.

Reichardt, I., Slane, D., El Kasmi, F., Knöll, C., Fuchs, R., Mayer, U., Lipka, V., and Jürgens, G. (2011). Mechanisms of functional specificity among plasma-membrane syntaxins in Arabidopsis. Traffic 12, 1269-1280.

Reichardt, I., Stierhof, Y. D., Mayer, U., Richter, S., Schwarz, H., Schumacher, K., and Jürgens, G. (2007). Plant cytokinesis requires de novo secretory trafficking but not endocytosis. Curr. Biol. 17, 2047-2053.

Richter, S., Geldner, N., Schrader, J., Wolters, H., Stierhof, Y. D., Rios, G., Koncz, C., Robinson, D. G., and Jürgens, G. (2007). Functional diversification of closely related ARF-GEFs in protein secretion and recycling. Nature 448, 488-492.

Richter, S., Müller, L. M., Stierhof, Y.D., Mayer, U., Takada, N., Kost, B., Vieten, A., Geldner, N., Koncz, C., and Jürgens, G. (2011). Polarised cell growth in Arabidopsis requires endosomal recycling mediated by GBF1related ARF exchange factors. Nat. Cell Biol. doi:10.1038/ncb2389

Rink, J., Ghigo, E., Kalaidzidis, Y., and Zerial, M. (2005). Rab conversion as a mechanism of progression from early to late endosomes. Cell 122, 735-749.

Robert, S., Chary, S. N., Drakakaki, G., Li, S., Yang, Z., Raikhel, N. V., and Hicks, G. R. (2008). Endosidin 1 defines a compartment involved in endocytosis of the brassinosteroid receptor BRI1 and the auxin transporters PIN2 and AUX1. Proc. Natl. Acad. Sci. U.S.A. 105, 8464-8469.
Robert, S., Kleine-Vehn, J., Barbez, E., Sauer, M., Paciorek, T., Baster, P., Vanneste, S., Zhang, J., Simon, S. Covanová, M., Hayashi, K., Dhonukshe, P., Yang, Z., Bednarek, S. Y., Jones, A. M., Luschnig, C., Aniento, F., Zažímalová, E., and Friml, J. (2010). ABP1 mediates auxin inhibition of clathrin-dependent endocytosis in Arabidopsis. Cell 143, 111-121.

Robinson, D. G., Jiang, L., and Schumacher, K. (2008). The endosomal system of plants: charting new and familiar territories. Plant Physiol. 147, 1482-1492.

Robinson, D. G., Oliviusson, P., and Hinz, G. (2005). Protein sorting to the storage vacuoles of plants: a critical appraisal. Traffic 6, 615-625.

Robinson, D. G., Scheuring, D. Naramoto, S., and Friml, J. (2011). ARF1 localizes to the Golgi and the trans-Golgi network. Plant Cell 23, 846-849.

Rojo, E., Gillmor, C. S., Kovaleva, V., Somerville, C. R., and Raikhel, N. V. (2001). VACUOLELESS1 is an essential gene required for vacuole formation and morphogenesis in Arabidopsis. Dev. Cell 1, 303-310.

Rojo, E., Sharma, V. K., Kovaleva, V., Raikhel, N. V., and Fletcher, J. C. (2002). CLV3 is localized to the extracellular space, where it activates the Arabidopsis CLAVATA stem cell signaling pathway. Plant Cell 14, 969-977.

Rojo, E., Zouhar, J., Kovaleva, V., Hong, S., and Raikhel, N. V. (2003). The AtC-VPS protein complex is localized to the tonoplast and the prevacuolar compartment in Arabidopsis. Mol. Biol. Cell 14, 361-369.

Roppolo, D., De Rybel, B., Tendon, V. D., Pfister, A., Alassimone, J., Vermeer, J. E., Yamazaki, M., Stierhof, Y. D., Beeckman, T., and Geldner, N. (2011). A novel protein family mediates Casparian strip formation in the endodermis. Nature 473, 380-383.

Rutherford, S., and Moore, I. (2002). The Arabidopsis Rab GTPase family: another enigma variation. Curr. Opin. Plant Biol. 5, 518-528.

Sanderfoot, A. A., Ahmed, S. U., MartyMazars, D., Rapoport, I., Kirchhausen, T., Marty, F., and Raikhel, N. (1998). A putative vacuolar cargo receptor partially colocalizes with AtPEP12p on a prevacuolar compartment in Arabidopsis roots. Proc. Natl. Acad. Sci. U.S.A. 95, 9920-9925.

Sanderfoot, A. A., Kovaleva, V., Bassham, D. C., and Raikhel, N. (2001). Interactions between syntaxins identify at least five
SNARE complexes within the Golgi/prevacuolar system of the Arabidopsis cell. Mol. Biol. Cell 12, 3733-3743.

Sanderfoot, A. A., Kovaleva, V., Zheng, H., and Raikhel, N. V. (1999). The t-SNARE AtVAM3p resides on the prevacuolar compartment in Arabidopsis root cells. Plant Physiol. 121, 929-938.

Sanmartín, M., Ordóñez, A., Sohn, E. J., Robert, S., Sánchez-Serrano, J. J., Surpin, M. A., Raikhel, N. V., and Rojo, E. (2007). Divergent functions of VTI12 and VTI11 in trafficking to storage and lytic vacuoles in Arabidopsis. Proc. Natl. Acad. Sci. U.S.A. 104, 3645-3650.

Scheuring, D., Viotti, C., Krüger, F., Künzl, F., Sturm, S., Bubeck, J., Hillmer, S., Frigerio, L., Robinson, D. G., Pimpl, P., and Schumacher, K. (2011). Multivesicular bodies mature from the transGolgi network/early endosome in Arabidopsis. Plant Cell 23, 3463-3481.

Schindelman, G., Morikami, A., Jung, J., Baskin, T. I., Carpita, N. C., Derbyshire, P., Mccann, M. C., and Benfey, P. N. (2001). COBRA encodes a putative GPI-anchored protein, which is polarly localized and necessary for oriented cell expansion in Arabidopsis. Genes Dev. 15, 1115-1127.

Seguí-Simarro, J. M., Austin, I. J. R., White, E. A., and Staehelin, L. A. (2004). Electron tomographic analysis of somatic cell plate formation in meristematic cells of Arabidopsis preserved by high-pressure freezing. Plant Cell 16, 836-856.

Shen, Y., Wang, J., Ding, Y., Lo, S. W., Gouzerh, G., Neuhaus, J. M., and Jiang, L. (2011). The rice RMR1 associates with a distinct prevacuolar compartment for the protein storage vacuole pathway. Mol. Plant 4, 854-868.

Shimada, T., Fuji, K., Tamura, K. Kondo, M., Nishimura, M., and Hara-Nishimura, I. (2003). Vacuolar sorting receptor for seed storage proteins in Arabidopsis thaliana. Proc. Natl. Acad. Sci. U.S.A. 100, 16095-16100.

Shimada, T., Kuroyanagi, M., Nishimura, M., and HaraNishimura, I. (1997). A pumpkin $72-\mathrm{kDa}$ membrane protein of precursor-accumulating vesicles has characteristics of a vacuolar sorting receptor. Plant Cell Physiol. 38, 1414-1420.

Shirakawa, M., Ueda, H., Shimada, T., Koumoto, Y., Shimada, T. L., Kondo, M., Takahashi, T., 
Okuyama, Y., Nishimura, M., and Hara-Nishimura, I. (2010). Arabidopsis Qa-SNARE SYP2 proteins localized to different subcellular regions function redundantly in vacuolar protein sorting and plant development. Plant J. 64, 924-935.

Sieburth, L. E., Muday, G. K., King, E. J., Benton, G., Kim, S., Metcalf, K. E., Meyers, L., Seamen, E., and Van Norman, J. M. (2006). SCARFACE encodes an ARF-GAP that is required for normal auxin efflux and vein patterning in Arabidopsis. Plant Cell 18, 1396-1411.

Silva, P. A., Ul-Rehman, R., Rato, C., Di Sansebastiano, G. P., and Malhó, R. (2010). Asymmetric localization of Arabidopsis SYP124 syntaxin at the pollen tube apical and sub-apical zones is involved in tip growth. BMC Plant Biol. 10, 179. doi:10.1186/1471-2229-10-179

Sohn, E. J., Kim, E. S., Zhao, M., Kim, S. J., Kim, H., Kim, Y. W., Lee, Y. J., Hillmer, S., Sohn, U., Jiang, L., and Hwang, I. (2003). Rhal, an Arabidopsis Rab5 homolog, plays a critical role in the vacuolar trafficking of soluble cargo proteins. Plant Cell 15, 1057-1070.

Sohn, E. J., Rojas-Pierce, M., Pan, S., Carter, C., Serrano-Mislata, A., Madueño, F., Rojo, E., Surpin, M., and Raikhel, N. V. (2007). The shoot meristem identity gene TFL1 is involved in flower development and trafficking to the protein storage vacuole. Proc. Natl. Acad. Sci. U.S.A. 104, 18801-18806.

Song, J., Lee, M. H., Lee, G. J., Yoo, C. M., and Hwang, I. (2006a). Arabidopsis EPSIN1 plays an important role in vacuolar trafficking of soluble cargo proteins in plant cells via interactions with clathrin, AP1, VTI11, and VSR1. Plant Cell 18, 2258-2274.

Song, X. F., Yang, C. Y., Liu, J., and Yang, W. C. (2006b). RPA, a class II ARFGAP protein, activates ARF1 and U5 and plays a role in root hair development in Arabidopsis. Plant Physiol. 141, 966-976.

Spitzer, C., Reyes, F. C., Buono, R., Sliwinski, M. K., Haas, T. J., and Otegui, M. S. (2009). The ESCRTrelated CHMP1A and B proteins mediate multivesicular body sorting of auxin carriers in Arabidopsis and are required for plant development. Plant Cell 21, 749-766.

Spitzer, C., Schellmann, S., Sabovljevic, A., Shahriari, M., Keshavaiah, C., Bechtold, N., Herzog, M., Müller, S., Hanisch, F. G., and Hülskamp, M. (2006). The Arabidopsis elch mutant reveals functions of an ESCRT component in cytokinesis. Development 133, 4679-4689.

Staehelin, L. A., Giddings, T. H. J., Kiss, J. Z., and Sack, F. D. (1990). Macromolecular differentiation of Golgi stacks in root tips of Arabidopsis and Nicotiana seedlings as visualized in high pressure frozen and freeze-substituted samples. Protoplasma 157, 75-91.

Stefano, G., Renna, L., Rossi, M., Azzarello, E., Pollastri, S., Brandizzi, F., Baluska, F., and Mancuso, S. (2010). AGD5 is a GTPase-activating protein at the trans-Golgi network. Plant J. 64, 790-799.

Steinmann, T., Geldner, N., Grebe, M., Mangold, S., Jackson, C. L., Paris, S., Gälweiler, L., Palme, K., and Jürgens, G. (1999). Coordinated polar localization of auxin efflux carrier PIN1 by GNOM ARF GEF. Science 286, 316-318.

Stierhof, Y. D., and El Kasmi, F. (2010). Strategies to improve the antigenicity, ultrastructure preservation and visibility of trafficking compartments in Arabidopsis tissue. Eur. J. Cell Biol. 89, 285-297.

Südhof, T. C., and Rothman, J. E. (2009). Membrane fusion: grippling with SNARE and SM proteins. Science 323, 474-477.

Suwastika, I. N., Uemura, T., Shiina, T., Sato, M. H., and Takeyasu, K. (2008). SYP71, a plant-specific QcSNARE protein, reveals dual localization to the plasma membrane and the endoplasmic reticulum in Arabidopsis. Cell Struct. Funct. 33, 185-192.

Swarup, R., Kargul, J., Marchant, A., Zadik, D., Rahman, A., Mills, R., Yemm, A., May, S., Williams, L., Millner, P., Tsurumi, S., Moore, I., Napier, R., Kerr, I. D., and Bennett, M. J. (2004). Structure-function analysis of the presumptive Arabidopsis auxin permease AUX1. Plant Cell 16, 3069-3083.

Szumlanski, A. L., and Nielsen, E. (2009). The Rab GTPase RabA4d regulates pollen tube tip growth in Arabidopsis thaliana. Plant Cell 21, 526-544.

Takano, J., Miwa, K., Yuan, L., Von Wirén, N., and Fujiwara, T. (2005). Endocytosis and degradation of BOR1, a boron transporter of Arabidopsis thaliana, regulated by boron availability. Proc. Natl. Acad. Sci. U.S.A. 102, 12276-12281.

Takano, J., Tanaka, M., Toyoda, A., Miwa, K., Kasai, K., Fuji, K., Onouchi, H., Naito, S., and Fujiwara, T. (2010). Polar localization and degradation of Arabidopsis boron transporters through distinct trafficking pathways. Proc. Natl. Acad. Sci. U.S.A. 107, 5220-5225.

Tanaka, H., Kitakura, S., De Rycke, R., De Groodt, R., and Friml, J. (2009). Fluorescence imaging-based screen identifies ARF GEF component of early endosomal trafficking. Curr. Biol. 19, 391-397.

Tanchak, M. A., Rennie, P. J., and Fowke, L. C. (1988). Ultrastructure of the partially coated reticulum and dictyosomes during endocytosis by soybean protoplasts. Planta 175 433-441.

Taylor, N. G. (2011). A role for Arabidopsis dynamin related proteins DRP2A/B in endocytosis; DRP2 function is essential for plant growth. Plant Mol. Biol. 76, 117-129.

Touihri, S., Knöll, C., Stierhof, Y. D. Müller, I., Mayer, U., and Jürgens, G. (2011). Functional anatomy of the Arabidopsis cytokinesis-specific syntaxin KNOLLE. Plant J. 68, 755-764

Tse, Y. C., Lo, S. W., Hillmer, S., Dupree, P., and Jiang, L. (2006). Dynamic response of prevacuolar compartments to brefeldin a in plant cells. Plant Physiol. 142, 1442-1459.

Tse, Y. C., Mo, B., Hillmer, S., Zhao, M., Lo, S. W., Robinson, D. G., and Jiang, L. (2004). Identification of multivesicular bodies as prevacuolar compartments in Nicotiana tabacum BY-2 Cells. Plant Cell 16, 672-693.

Tyrrell, M., Campanoni, P., Sutter, J. U., Pratelli, R., Paneque, M., Sokolovski, S., and Blatt, M. R. (2007). Selective targeting of plasma membrane and tonoplast traffic by inhibitory (dominant-negative) SNARE fragments. Plant J. 51, 1099-1115

Ueda, T., Uemura, T., Sato, M. H., and Nakano, A. (2004). Functional differentiation of endosomes in Arabidopsis cells. Plant J. 40, 783-789.

Ueda, T., Yamaguchi, M., Uchimiya, H., and Nakano, A. (2001). Ara6, a plant-unique novel type Rab GTPase, functions in the endocytic pathway of Arabidopsis thaliana. EMBO J. 20, 4730-4741.

Uemura, T., Morita, M. T., Ebine, K., Okatani, Y., Yano, D., Saito, C., Ueda, T., and Nakano, A. (2010). Vacuolar/pre-vacuolar compartment Qa-SNAREs VAM3/SYP22 and PEP12/SYP21 have interchangeable functions in Arabidopsis. Plant J. 64, 864-873.

Uemura, T., Ueda, T., Ohniwa, R. L., Nakano, A., Takeyasu, K., and Sato, M. H. (2004). Systematic analysis of SNARE molecules in Arabidopsis: dissection of the post-Golgi network in plant cells. Cell struct. Funct. 29, 49-65.
Van Damme, D., Gadeyne, A., Vanstraelen, M., Inzé, D., Van Montagu, M. C., De Jaeger, G., Russinova, E., and Geelen, D. (2011). Adaptin-like protein TPLATE and clathrin recruitment during plant somatic cytokinesis occurs via two distinct pathways. Proc. Natl. Acad. Sci. U.S.A. 108, 615-620.

Viotti, C., Julia Bubeck, J., Stierhof, Y. D., Krebs, M., Langhans, M., Van Den Berg, W., Van Dongen, W., Richter, S., Geldner, N., Takano, J., Jürgens, G., De Vries, S. C., Robinson, D. G., and Schumacher, K. (2010). Endocytic and secretory traffic in Arabidopsis merge in the trans-Golgi network/early endosome, an independent and highly dynamic organelle. Plant Cell 22, 1344-1357.

Waizenegger, I., Lukowitz, W., Assaad, F. F., Schwarz, H., Jürgens, G., and Mayer, U. (2000). The Arabidopsis KNOLLE and KEULE genes interact to promote vesicle fusion during cytokinesis. Curr. Biol. 10, 1371-1374.

Wang, H., Tse, Y. C., Law, A. H., Sun, S. S., Sun, Y. B., Xu, Z. F., Hillmer, S., Robinson, D. G., and Jiang, L. (2010). Vacuolar sorting receptors (VSRs) and secretory carrier membrane proteins (SCAMPs) are essential for pollen tube growth. Plant J. 61, 826-838.

Wang, H., Zhuang, X. H., Hillmer, S., Robinson, D. G., and Jiang, L. W. (2011). Vacuolar sorting receptor (VSR) proteins reach the plasma membrane in germinating pollen tubes. Mol. Plant 4, 845-853.

Wang, J., Cai, Y., Miao, Y., Lam, S. K., and Jiang, L. (2009). Wortmannin induces homotypic fusion of plant prevacuolar compartments. J. Exp. Bot. 60, 3075-3083.

Yano, D., Sato, M., Saito, C., Sato, M. H., Morita, M. T., and Tasaka, M. (2003). A SNARE complex containing SGR3/AtVAM3 and ZIG/VTI11 in gravity-sensing cells is important for Arabidopsis shoot gravitropism. Proc. Natl. Acad. Sci. U.S.A. 100 8589-8594.

Yoo, C. M., Wen, J., Motes, C. M., Sparks, J. A., and Blancaflor, E. B. (2008). A class I ADP-ribosylation factor GTPase-activating protein is critical for maintaining directional root hair growth in Arabidopsis. Plant Physiol. 147, 1659-1674.

Zhang, G. F., and Staehelin, L. A. (1992). Functional compartmentation of the Golgi apparatus of plant cells: immunocytochemical analysis of high-pressure frozen- and freeze-substituted sycamore maple 
suspension culture cells. Plant Physiol. 99, 1070-1083.

Zhao, Y., Yan, A., Feijó, J. A., Furutani, M., Takenawa, T., Hwang, I., Fu, Y., and Yang, Z. (2010). Phosphoinositides regulate clathrindependent endocytosis at the tip of pollen tubes in Arabidopsis and tobacco. Plant Cell 22, 4031-4044.

Zheng, H., Bednarek, S. Y., Sanderfoot, A. A., Alonso, J., Ecker, J. R., and Raikhel, N. (2002). NPSN11 is a cell plate-associated SNARE protein that interacts with the syntaxin KNOLLE. Plant Physiol. 129, 530-539.

Zheng, H., and Staehelin, L. A. (2011). Protein storage vacuoles are transformed into lytic vacuoles in root meristematic cells of germinating seedlings by multiple, cell type-specific mechanisms. Plant Physiol. 155, 2023-2035.

Zhuang, X., Jiang, J., Li, J., Ma, Q., Xu, Y., Xue, Y., Xu, Z., and Chong, K. (2006). Over-expression of OsAGAP, an ARF-GAP, interferes with auxin influx, vesicle trafficking and root development. Plant J. 48, 581-591.

Zouhar, J., Muñoz, A., and Rojo, E. (2010). Functional specialization within the vacuolar sorting receptor family: VSR1, VSR3 and VSR4 sort vacuolar storage cargo in seeds and vegetative tissues. Plant J. 64, 577-588.

Zouhar, J., Rojo, E., and Bassham, D. C. (2009). AtVPS45 is a positive regulator of the SYP41/SYP61/VTI12 SNARE complex involved in trafficking of vacuolar cargo. Plant Physiol. 149, 1668-1678.

Zuo, J., Niu, Q. W., Nishizawa, N., Wu, Y., Kost, B., and Chua, N. H. (2000). KORRIGAN, an Arabidopsis endo1,4-beta-glucanase, localizes to the cell plate by polarized targeting and is essential for cytokinesis. Plant Cell 12, 1137-1152.

Zwiewka, M., Feraru, E., Möller, B., Hwang, I., Feraru, M. I., KleineVehn, J., Weijers, D., and Friml, J. (2011). The AP-3 adaptor complex is required for vacuolar function in Arabidopsis. Cell Res. 21, 1711-1722.

Conflict of Interest Statement: The authors declare that the research was conducted in the absence of any commercial or financial relationships that could be construed as a potential conflict of interest.

Received: 26 September 2011; paper pending published: 16 October 2011; accepted: 19 December 2011; published online: 04 January 2012.

Citation: Park $M$ and Jürgens $G$ (2012) Membrane traffic and fusion at postGolgi compartments. Front. Plant Sci. 2:111. doi: 10.3389/fpls.2011.00111

This article was submitted to Frontiers in Plant Physiology, a specialty of Frontiers in Plant Science.

Copyright (ㄷ) 2012 Park and Jürgens. This is an open-access article distributed under the terms of the Creative Commons Attribution Non Commercial License, which permits non-commercial use, distribution, and reproduction in other forums, provided the original authors and source are credited. 